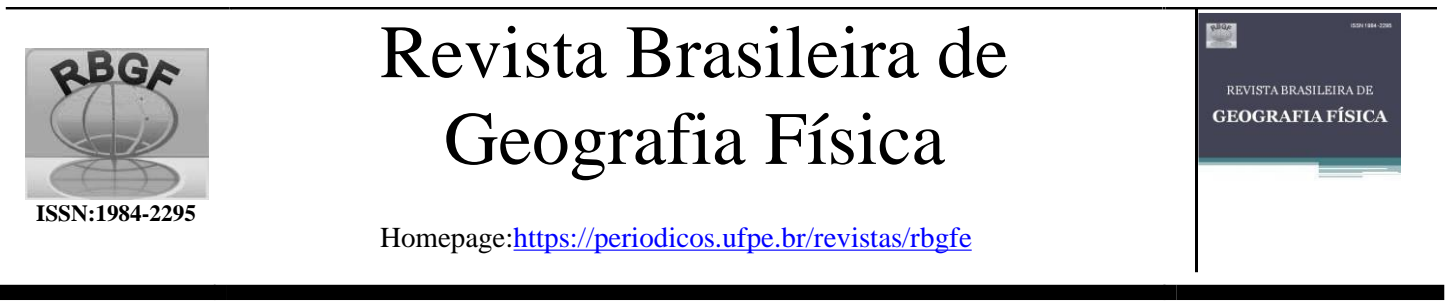

\title{
Assinatura Energética dos Manguezais no Domínio Costeiro Brasileiro
}

\author{
Janaina Barbosa da Silva. Profa. Dra. Da Universidade Federal de Campina Grande; \\ janainasimov@yahoo.com.br \\ Maria Fernanda Abrantes Torres. Profa. Dra. Da Universidade Federal de Pernambuco; \\ datorres@hotmail.com
}

Artigo recebido em 20/01/2021 e aceito em 05/07/2021

\begin{abstract}
RE S U M O
Esta pesquisa objetivou detalhar, a partir de uma visão sistêmica, o ecossistema manguezalna escala Brasil, baseando-se na escala de Unidades, e nas definições de ecossistema. A multiplicida de de fitofisionomias de mangues ao longo da costa brasileira requer conhecimentos específicos acerca dos agentes condicionantes que explicam tais configurações, assim buscou-se detalhar a assinatura energética da costa brasileira para melhor compreensão da dispersão, diversidade e zonação da vegetação de mangue. A base de dados foi secundária, coletados em artigos nacionais e internacionais, teses e dissertações e sites oficiais. Como resultados tem-se: 1- Foram identificadas nove Unidades Ambientais para o Domínio Costeiro brasileiro, com base em suas características gerais, onde estudo anterior estabelecia oito Unidades; 2- Os fluxogramas para cada Unidade foram elaborados a partir das energias subsidiárias, ou seja, insolação média anual; temperatura média anual; precipitação média a nual; nutrientes; vazão média a nual; a mplitude média de ma ré, resultando a ssim em uma caracterização a mbiental para cada Unidade. 3-Como resposta a Assinatura Energética de cada Unidade, foi possível identificar padrões de dispersão/ocorrência de espécies de man gue com ocorrência. 4- Para o Brasil o gênero de maior diversidade é Rhizophora, esse ocorre em toda a costa brasileira. Contudo, somente a Rhizophora mangle está presente desde a foz do Rio Oia poque-AM até Santa Catarina. A R. racemosa e $R$. harrisonii se dispersam desde a Região Norte com seu limite sul no Delta do Rio Parnaíba-PI no Nordeste brasileiro.
\end{abstract}

Palavras chave: estrutura e diversidade; espécies de mangue; apicum; tensor; estressor; energia subsidiária.

\section{Energy Signature of Manguezals in the Brazilian Coastal Domain}

\section{A B S T R A C T}

This research aimed to detail, from a systemic view, the mangrove ecosystem on the Brazil scale, based on the Units scale, and on the ecosystem definitions. The multiplicity of mangrove phytophysiognomies along the Brazilian coast requires specific knowledge about the conditioning agents that explain such configurations, so we sought to detail the energy signature of the Brazilian coast to better understand the dispersion, diversity and zoning of the mangrove vegetation. The database was secondary, collected in national and international articles, theses and dissertations and official websites. The results are: 1- Nine EnvironmentalUnits for the Brazilian CoastalDomain were identified, based on their general characteristics, where a previous study established eight Units; 2 - The flowcharts for each Unit were prepared based on subsidiary energies, that is, a verage annual sunshine; annual avera ge temperature; a verage annual precipitation; nutrients; a verage annualflow; a vera ge tidal range, thus resulting in an environmentalcharacterization for each Unit. 3- In response to the Energy Signature of each Unit, it was possible to identify patterns of dispersion / occurrence of mangrove species with occurrence. 4- For Brazil, the most diverse genus is Rhizophora, which occurs throughout the Brazilian coast. However, only the Rhizophora mangle is present from the mouth of the Oiapoque-AM to Santa Catarina. R. racemosa and R. harrisonii are dispersed from the North Region with its southern limit in the Delta of the river Parnaíba-PI in the Northeast of Brazil.

Keyworlds: structure and diversity; mangrove species; salt flats; stressor; subsidiary energy.

\section{Introdução}

É possível observar que, para o estudo de ambientes naturais há a necessidade de alinhar as pesquisas de uma paisagem a um determinado espaço-tempo, a partir de uma visão sistêmica.
Walsh (1974), para o estudo dos manguezais, ressalta algumas características basais para a sua existência com excelente desenvolvimento. São elas: Temperaturas inferiores a $20^{\circ} \mathrm{C}$; Amplitude térmica menor que $5^{\circ} \mathrm{C}$; substrato de depósitos 
Revista Brasileira de Geografia Física v.014, n.04 (2021) 2286-2303.

tipicamente lamosos; precipitações superiores a $1.500 \mathrm{~mm} /$ ano sem longo período de seca; marés com amplitudes elevadas. Tais características corroboram com a definição de ecossistema de Odum (1979), quando afirma que ecossistema é onde ocorre interações entre os organismos vivos e seu ambiente abiótico, que obedecem a fatores limitantes no espaço-tempo, podendo ser de certa forma dirigido e previsível e, consequentemente, passível de monitoramento.

Cada manguezal é único do ponto de vista do que Odun (1969) relaciona quando da interação entre as forças naturais e as respostas do ambiente, em que fatores abióticos como radiação solar, energia das marés, aporte de água doce, entrada de nutrientes no sistema, entre outros. A utilização máxima desses fatores para o desenvolvimento do ecossistema é uma resposta a energia disponível no ambiente, denominada de uso máximo da assinatura energética. Quanto maior a disponibilidade e abundância dessas energias, maior desenvolvimento será alcançado pelos componentes vegetais. Essas forças externas, portanto, constituem importantes subsídios ao ecossistema manguezal. De acordo com Lugo e Snedaker (1974), essas forças subsidiárias ou a assinatura energética que regem os processos de desenvolvimento do manguezal, atuam desde os processos iniciais à estrutura final.

Ao analisar a assinatura energética para os manguezais, é possível compreender que, a escala espacial a nível global de distribuição dos manguezais é influenciada sobremaneira pela radiação solar e a temperatura, seguidapela energia das marés. Em uma escala regional, o aporte de água doce regulado pela vazão dos rios e a precipitação irão ditar a diversidade de espécies de mangue, por exemplo. Na escala local, no entanto, é o aporte de nutrientes resultante das ações das energias supracitadas que irá subsidiar o desenvolvimento e a manutenção desta vegetação.

Para Taiz e Zieger (2004), a radiação solar é importante para todos os vegetais que fazem fotossíntese (transforma o $\mathrm{CO}_{2}$ atmosférico em energia metabólica), afinal eles tem sua origem nessa energia, sendo um dos fatores preponderantes ao crescimento da vegetação e seu desenvolvimento, bem como ao uso na respiração (regulação dos estômatos) e da absorção de $\mathrm{CO}_{2}$. Banerjee (1993) e Pascoalini et al. (2014) afirmam que a vegetação de manguezal se estende geralmente da foz dos estuários até a influência do fluxo de água da maré alta do sistema fluvial interior, essas variações além de atuar na salinidade, também eliminam substâncias tóxicas (sulfato de hidrogênio), oxigenam os sedimentos, transportam sementes e nutrientes.

Nos estuários, a água doce oriunda dos rios é essencial à dissolução dos sais, bem como a forçante hidrodinâmica limitante à entrada das marés, gerando padrões de circulação, gradientes de salinidade, transporte de sedimentos e nutrientes. Contudo, essas águas também podem trazer consigo poluentes e patógenos. É a sazonalidade das precipitações que causa as condicionantes à variação da salinidade, onde o período de redução dessas tem-se, consequentemente, a diminuição da vazão, que acarreta uma maior intrusão salina e queda no transporte de sedimentos, enquanto o aumento da vazão acarreta queda expressiva na salinidade, principalmente (Gens, Lessa e Cirano, 2008).

Segundo Vila Nova, Torres e Coelho (2017, p.3), "as espécies arbóreas do ecossistema manguezal têm a capacidade de alterar a condição dos solos adjacentes ao seu sistema radicular e desempenhar um papel ativo nas reações químicas neste compartimento ambiental". Em estudo realizado porMadi, Boegere Reissmann (2015), as espécies de mangue apresentaram estratégias distintas relacionadas ao armazenamento e uso de nutrientes, particularmente devido às várias estratégias utilizadas pelas plantas para a manutenção do equilíbrio iônico. Mas, dentre as energias subsidiárias, uma delas irá atuar de forma preponderante em detrimento da outra, gerando assim uma certa pressão sobre a vegetação e gerando um certo grau de tensão.

Neste contexto, a presente pesquisa objetivou: 1 - Compartimentar a costa brasileira a partir de dados da Assinatura energética para os manguezais; 2- Elaborar fluxogramas para entendimento das energias subsidiárias a presença e desenvolvimento dos manguezais; 3 - Estabelecer padrões estruturais dos manguezais brasileiros; 4 Identificar a dispersão das espécies de mangue na costa brasileira.

\section{Metodologia}

Para a realização desta pesquisa pode-se dizer que foram necessários três momentos consecutivos, com base em dados secundários, coletados em artigos nacionais e internacionais, teses e dissertações e sites oficiais governamentais. Em um primeiro momento, foi necessário a compreensão do que rege um ecossistema natural, sua existência e respectiva limitação, buscando-se compreender os conceitos de níveis hierárquicos e assinatura energética; no segundo momento, procurou-se definir a escala de estudo para a 
Revista Brasileira de Geografia Física v.014, n.04 (2021) 2286-2303.

compreensão da assinatura energética ou energias subsidiárias que regem o ecossistema manguezal no Brasil; por fim, buscou-se estabelecer as energias subsidiárias dominantes no Brasil a partir das Unidades propostas por Schaeffer-Novelli et al. (1990), e nas definições de ecossistema segundo Odum (1979) e Walsh (1974).

As energias subsidiárias para o manguezal são seis de acordo com Schaeffer-Novelli et al (1990): 1- radiação, que é o número de dias de Sol;
2- temperatura, coma média anual; 3 - precipitação, podendo ser anual e ou meses de chuvas; 4nutrientes relativos aos sedimentos e tipos de solos do litoral; 5- marés, com as máximas medidas ou estimadas; 6- aporte hídrico, relativo à vazão dos rios, podendo ser uma média ou aquela que sobressair na Unidade. Por fim o tensor, que é a energia subsidiária prevalecente e que responderá na vegetação de mangue, ditando assim a altura do bosque e diversidade de espécies de mangue (Figura 01).

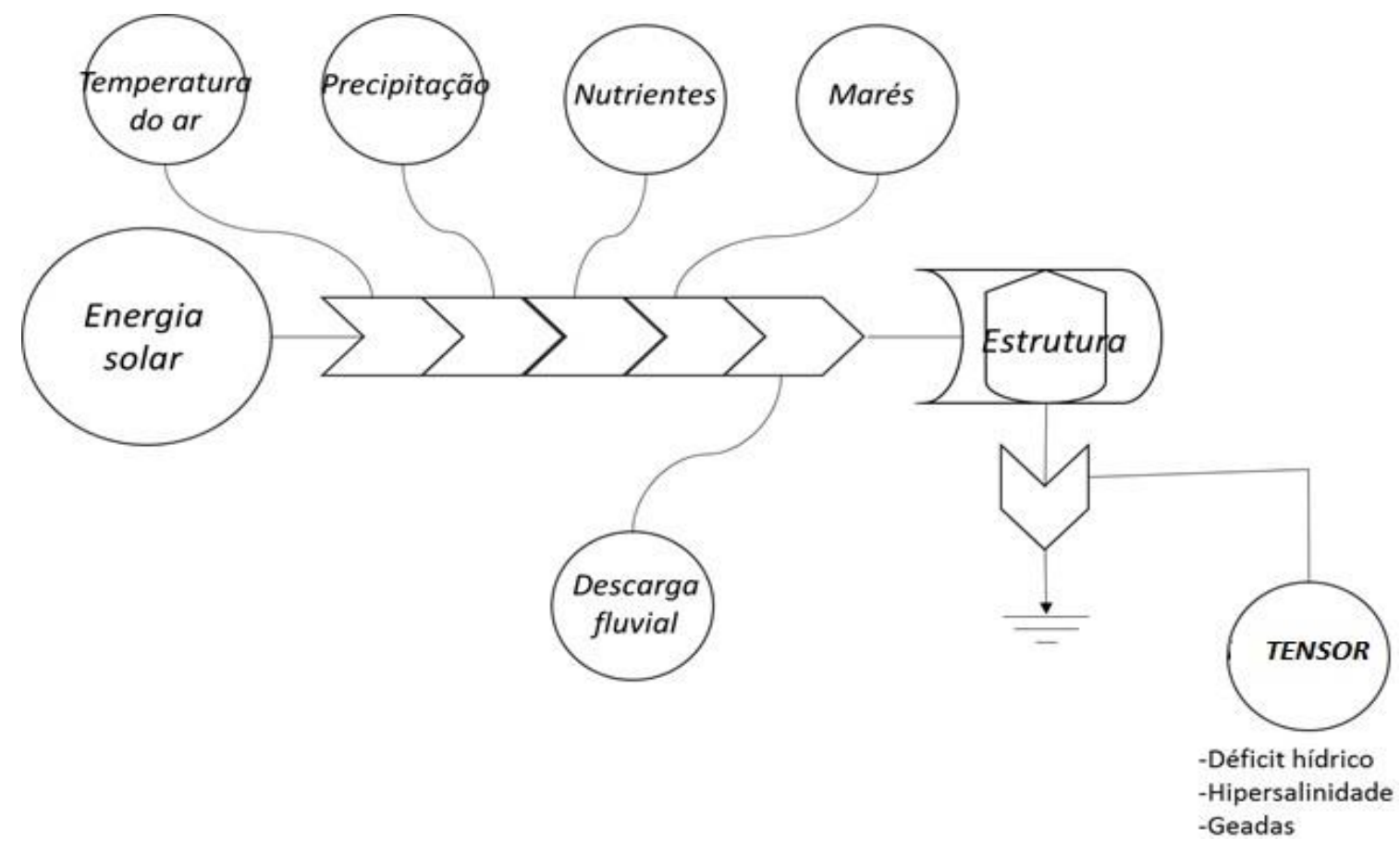

Figura 1: Assinatura energética do manguezal segundo modelo conceitual original de Odum (1968). Fonte: Adaptado e traduzido de Schaeffer-Novelli et al. (1990).

\section{Desenvolvimento}

1- Compartimentar a costa brasileira a partir de dados da Assinatura energética para os manguezais;

Ao analisar as características das Unidades costeiras propostas por SchaefferNovelli et al. (1990), que propuseram a divisão da Costa brasileira em oito
Unidades, identificou-se que a partir dos dados das energias subsidiárias para cada uma delas, tem-se que a Unidade IV deveria ser dividida em duas, ficando assim, a partir de agora nove unidades e não mais oito. No Quadro 1 é apresentado os limites de cada Unidade com suas latitudes antigas e atuais, enquanto na Figura 1 tem-se a localização das Unidades atualizada. Mais informações serão apresentadas ao longo dos resultados. 
Revista Brasileira de Geografia Física v.014, n.04 (2021) 2286-2303.

Quadro 1: Número de Unidades do Domínio Costeiro Brasileiro segundo Schaeffer-Novelli et al. (1990) e a proposta do presente estudo.

\begin{tabular}{|c|c|c|c|c|c|}
\hline \multicolumn{6}{|c|}{ DOMÍNIO COSTEIRO BRASILEIRO } \\
\hline \multicolumn{3}{|c|}{ SEGUNDO SCHAEFFER-NOVELLI et al. (1990) } & \multicolumn{3}{|c|}{ SILVA E TORRES (RESULTADO) } \\
\hline UNIDADE & INÍCIO & FIM & UNIDADE & INÍCIO & FIM \\
\hline I & $\begin{array}{l}04^{\circ} 37^{\prime} \mathrm{N} \\
\text { Oiapoque-AP }\end{array}$ & $\begin{array}{r}01^{\circ} 40{ }^{\prime} \mathrm{N} \text { CABO } \\
\text { NORTE-AP }\end{array}$ & I & $\begin{array}{l}4^{\circ} 40^{\prime} \mathrm{N} \\
\text { Oiapoque-AP }\end{array}$ & $\begin{array}{r}1^{\circ} 40 ` \mathrm{~N} \\
\mathrm{CABO} \\
\text { NORTE- } \\
\text { AP }\end{array}$ \\
\hline II & $\begin{array}{l}01^{\circ} 40^{\prime} \mathrm{N} \text { CABP } \\
\text { NORTE-AP }\end{array}$ & $\begin{array}{r}00^{\circ} 36^{\prime} \mathrm{N} \text { Ponta } \\
\text { Curuçá - PA }\end{array}$ & II & $\begin{array}{l}1^{\circ} 40^{\prime} \mathrm{N} \\
\text { CABO } \\
\text { NORTE-AP }\end{array}$ & $\begin{array}{r}0^{\circ} 36^{`} \mathrm{~N} \\
\text { Ponta } \\
\text { Curuçá - } \\
\text { PA }\end{array}$ \\
\hline III & $\begin{array}{l}00^{\circ} 36^{\prime} \mathrm{N} \text { Ponta } \\
\text { Curuçá - PA }\end{array}$ & $\begin{array}{r}02^{\circ} 15^{\prime} \text { S Ponta } \\
\text { Mangue Seco - } \\
\text { MA }\end{array}$ & III & $\begin{array}{l}0^{\circ} 36^{`} \mathrm{~N} \text { Ponta } \\
\text { Curuçá - PA }\end{array}$ & $\begin{array}{r}2^{\circ} 15^{\prime} \mathrm{S} \\
\text { Ponta } \\
\text { Mangue } \\
\text { Seco-MA }\end{array}$ \\
\hline IV & $\begin{array}{l}02^{\circ} 15^{\prime} \mathrm{S} \text { Ponta } \\
\text { Mangue Seco - } \\
\text { MA }\end{array}$ & $\begin{array}{r}05^{\circ} 08^{\prime} \mathrm{S} \text { Cabo } \\
\text { Calcanhar-RN }\end{array}$ & IV & $\begin{array}{l}2^{\circ} 15^{\prime} \text { S Ponta } \\
\text { Mangue Seco } \\
\text { - MA }\end{array}$ & $\begin{array}{r}4^{\circ} 37^{\prime} \mathrm{S} \\
\text { Ponta } \\
\text { Grossa } \\
\text { (Icapuí-CE) }\end{array}$ \\
\hline $\mathrm{V}$ & $\begin{array}{l}05^{\circ} 08^{\prime} \text { S Cabo } \\
\text { Calcanhar-RN }\end{array}$ & $\begin{array}{r}13^{\circ} 00^{\prime} \mathrm{S} \\
\text { Recôncavo } \\
\text { Baiano-BA }\end{array}$ & $\mathrm{V}$ & $\begin{array}{l}\text { 4³7’S Ponta } \\
\text { Grossa } \\
\text { (Icapuí-CE) }\end{array}$ & $\begin{array}{r}05^{\circ} 08^{\prime} \mathrm{S} \\
\text { Cabo } \\
\text { Calcanhar - } \\
\text { RN }\end{array}$ \\
\hline VI & $\begin{array}{ll}13^{\circ} 00^{\prime} & \mathrm{S} \\
\text { Recôncavo } & \\
\text { Baiano - BA }\end{array}$ & $\begin{array}{r}23^{\circ} 00^{\prime} \mathrm{S} \text { Cabo } \\
\text { Frio - RJ }\end{array}$ & VI & $\begin{array}{ll}05^{\circ} 08^{\prime} & \mathrm{S} \\
\text { Cabo } & \\
\text { Calcanhar } & - \\
\text { RN } & \end{array}$ & $\begin{array}{r}13^{\circ} 00^{\prime} \mathrm{S} \\
\text { Recôncavo } \\
\text { Baiano - } \\
\text { BA }\end{array}$ \\
\hline VII & $\begin{array}{l}23^{\circ} 00^{\prime} \mathrm{S} \text { Cabo } \\
\text { Frio - RJ }\end{array}$ & $\begin{array}{r}29^{\circ} 20^{\prime} \text { S Torres - } \\
\text { RS }\end{array}$ & VII & $\begin{array}{l}13^{\circ} 00^{\prime} \mathrm{S} \\
\text { Recôncavo } \\
\text { Baiano - BA }\end{array}$ & $\begin{array}{r}23^{\circ} 00^{\prime} \mathrm{S} \\
\text { Cabo Frio - } \\
\text { RJ }\end{array}$ \\
\hline VIII & $\begin{array}{l}29^{\circ} 20^{\prime} \text { S Torres } \\
\text {-RS }\end{array}$ & $\begin{array}{r}33^{\circ} 45^{\prime} \text { S Chuí- } \\
\text { RS }\end{array}$ & VIII & $\begin{array}{ll}23^{\circ} 00^{\prime} & \mathrm{S} \\
\text { Cabo Frio } & - \\
\text { RJ }\end{array}$ & $\begin{array}{r}29^{\circ} 20^{\prime} \mathrm{S} \\
\text { Torres -RS }\end{array}$ \\
\hline & & & IX & $\begin{array}{l}29^{\circ} 20^{\prime} \mathrm{S} \\
\text { Torres -RS }\end{array}$ & $\begin{array}{r}33^{\circ} 45^{\prime} \mathrm{S} \\
\text { Chuí-RS } \\
\end{array}$ \\
\hline
\end{tabular}


Unidades Fisiográficas dos Manguezais Brasileiros

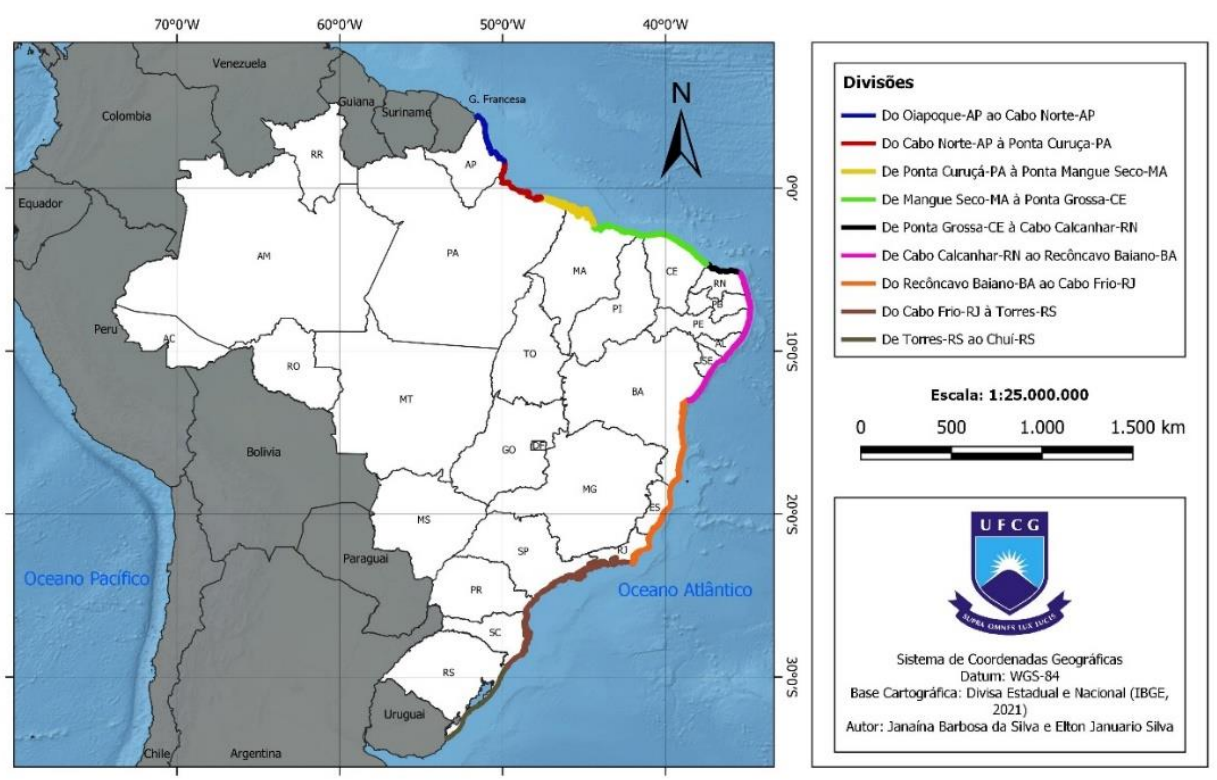

Figura 2: Mapa de localização das Unidades Fisiográficas dos Manguezais Brasileiros.

Com base nas características de cada Unidade, foi possível elaborar um fluxograma com os valores médio/anual e representar assim a energia subsidiária para cada Unidade costeira, com dados de insolação, temperatura, precipitação e maré, onde para a maioria das Unidades também se tem os valores de vazão. Foi descrito também a predominância dos tipos de sedimentos, tipos de estrutura dos bosques, bem como a energia que resulta nas características da vegetação de mangue, nominada como tensor.

Unidade I - Da Região do Oiapoque - $\mathrm{AP}\left(4^{\circ} 30^{\prime} \mathrm{N}\right)$ ao Cabo Norte - AP $\left(01^{\circ} 40^{\prime} \mathrm{N}\right)$.

De acordo com Funari e Tarifa (2017), a média de insolação é de $2.500 \mathrm{~h} / \mathrm{Sol} / \mathrm{ano}$, como resposta à proximidade do Equador e relevo plano. Em relação à temperatura, praticamente não há uma variação anual, com a média entre $26^{\circ} \mathrm{C}$ e $27^{\circ} \mathrm{C}$, onde o mês de setembro é o mais quente (CLIMATE-DATA, 2020a), sendo a Linha do Equador e a maritimidade os regentes dessa baixa amplitude térmica. Quanto à precipitação, tem-se que a maior concentração de chuvas está no Oiapoque e litoral com 2.700 a $2.900 \mathrm{~mm}$, (Cunha, Souza e Cunha, 2010). A vazão do Rio Amazonas domina toda a Unidade I, com descarga máxima no mês de maio, com $275.000 \mathrm{~m} 3 / \mathrm{s}$. toda essa massa de água doce e líquida traz consigo Sedimentos e Nutrientes de matriz pelítica (sedimentos de argila e silte que se movem junto ao fundo) na área estuarina e plataforma continental com valor de descarga sólida de 1 a $13 \times 10^{8}$ t por ano (estimativa em 1991) (Santos et al., 2007; Gallo e Vinzon, 2015; Mendes, 2003; Prost E Rabelo, 1996). As marés, de acordo com Gallo e Vinzon (2015); Prost e Rabelo (1996) e Souza Filho (2005), têm amplitude média de seis metros na sizígia, dominada por fortes correntes, as quais são responsáveis por uma grande erosão no litoral amapaense e redução das áreas de mangue.

Os manguezais do Amapá apresentam uma característica típica, pois não apresentam conexões com baías e estuários (Mendes, 2003). De acordo com Schaeffer-Novelli et al. (1990), SchaefferNovelli e Molero (1988), Prost e Rabelo (1996), há o predomínio de Avicennia associada a espécies de várzea, por vezes com palmeiras. Abreu et al. (2016) identificaram a presença desta na maior parte da faixa costeira da Unidade I. A espécie Laguncularia racemosa foi identificada nessa Unidade por Abreu et al. (2016) e Prost e Rabelo (1996) desde a Foz do Rio Amapá até o município de Sucuriju, enquanto Rhizophora mangle apresenta distribuição restrita nas várzeas interiores. Rhizophora harrisonii foi registrada na Ilha de Maracá e Sucuriju e Rhizophora racemosa foi assinalada no Rio Amapá e Sucuriju.

Em alguns trechos há uma zonação de espécies do gênero Spartina, Anonna, Avicennia e Rhizophora ( $R$. mangle, $R$. harrisonii e $R$. racemosa), como no Cabo Orange, Rio Amapá, Ilha de Maracá e Sucuriju. A zonação das espécies é favorecida pelas energias subsidiárias de 
Revista Brasileira de Geografia Física v.014, n.04 (2021) 2286-2303.

sedimentos e macromarés, mas nas reentrâncias abrigadas e de menor energia costeira. Os bosques variam entre aqueles que apresentam proporcionalidades na presença das espécies de Rhizophora ssp e Avicennia ssp a quase monoespecíficos, onde predomina em mais de $80 \%$ uma das espécies supracitadas (Fernandes, Nascimento e Carvalho, 2007; Sales et al., 2009; Silva, 2018; Carvalho e Jardim, 2017; Rodriguez, 2019, Schaeffer-Novelli e Molero, 1988; Prost e Rabelo, 1996).
Assim, a assinatura energética para os manguezais da Unidade I está destacada na Figura 3 , onde são apresentados os valores médios da insolação, temperatura, precipitação, nutrientes, vazão e marés, que acabam por refletir na estrutura do manguezal, que se caracteriza pela presença de bosques monoespecífico e o consórcio com espécies de várzea. A baixa diversidade de espécies de mangue e a altura do dossel é uma resposta ao tensor. A amplitude de maré $(10 \mathrm{a} 11 \mathrm{~m})$ é o tensor para essa Unidade (I), pois causa erosão e depósito de sedimentos.

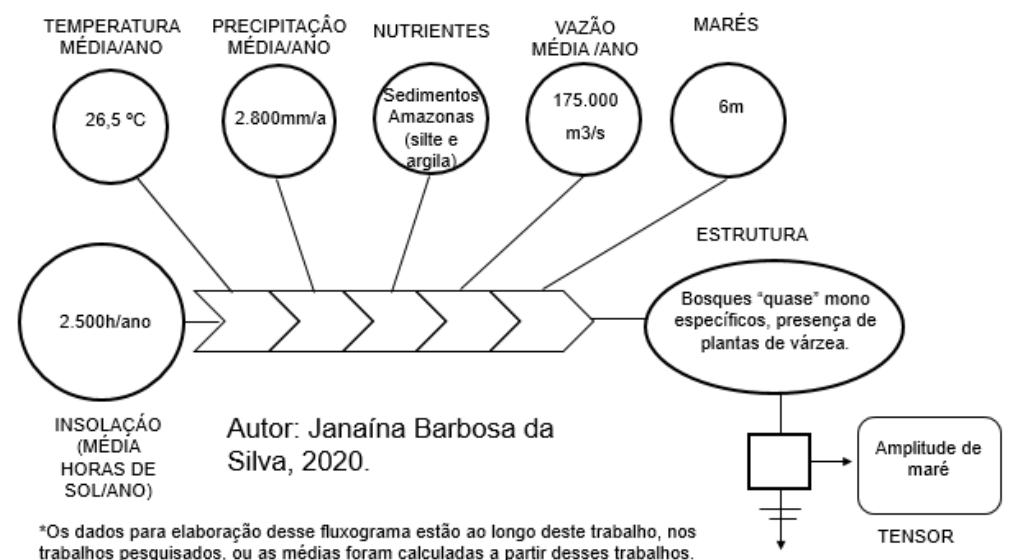

Figura 3: Assinatura energética dos manguezais da Unidade I, totalmente inserida no Estado do

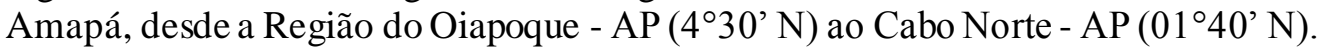

Unidade II: Do Cabo Norte - AP $\left(01^{\circ} 40^{\prime} N\right)$ à Ponta Curuçá - PA (00³6’S).

Apresenta características climáticas análogas a Unidade I, e de acordo com Monteiro, El-Robrinni e Alves (2015), El-Robrinni et al., (2020); Torres e El-Rodrinni (2020) e Funari e Tarifa (2017), apresenta baixas variações de insolação com uma média de dias de Sol de 2.600/h/Sol/ano, decorrente da baixanebulosidade; temperatura média de $27^{\circ} \mathrm{C} / \mathrm{ano}$; pluviosidade de $2.500 \mathrm{~mm} / \mathrm{ano}$; as marés registram amplitudes de $6 \mathrm{~m}$. Uma característica marcante desta Unidade é a descarga de dois grandes rios, o Amazonas e o Tocantins. De acordo com a ANA (2020), a vazão do Rio Tocantins é controlada, uma vez que há hidrelétricas em seu curso, e segundo Santos e Oliveira (2016), a vazão descritiva média foi de $10.534,53 \mathrm{~m}^{3} / \mathrm{s}$. De acordo com o sítio Amazônia.org (2020), o Rio Amazonas tem sua vazão média final em $200.000 \mathrm{~m}^{3} / \mathrm{s}$. Quanto aos nutrientes, esses variam sazonalmente e longitudinalmente com predomínio de sedimentos lamosos de silte e argila, ricos em matéria orgânica em áreas de "falsas rias". De acordo com Prost e
Rabelo (1996), a diferença da Unidade II para a Unidade I é basicamente “...em sua maioria, em posição abrigada, protegidos por praias e dunas e desenvolvem-se nas margens dos estuários" (p.114).

As espécies de mangue encontradas nesta Unidade são: Avicennia germinas, Avicennia schaueriana; o gênero Rhizophora apresentou a maior diversidade de espécies, com um total de três, $R$. mangle, $R$. harrisonii e $R$. racemosa (Schaeffer-Novelli e Molero,1988; Abreu et al., 2016; Prost e Rabelo, 1996). Torres e El-Rofrinni (2020) ressaltam que em algumas áreas, tais como em Bailique, são comuns a presença de aninga (Montrichardia arborescens L. schott) e de buriti (Mauritia flexuosa L.F.).

Mendes (2003) destaca que há zonação nessa Unidade, sendo "mais ou menos monoespecífica" e gradientes de sucessão como resposta aos processos de sedimentação e hidrológico. Essas configurações respondem a energia subsidiárias como sedimentos fluidos e predomínio de argila, no caso de $R$. mangle, enquanto Avicennia ocorre em sedimentos mais 
Revista Brasileira de Geografia Física v.014, n.04 (2021) 2286-2303.

consolidados com predomínio de siltes e gradiente topográfico crescente. Na Figura 4 é possível identificar todas as energias e seus valores para a Unidade II. Quanto à estrutura da vegetação essa é basicamente em bosques monoespecíficos, como resposta ao tensor, que nessa Unidade é o superávit hídrico decorrente da vazão dos rios.

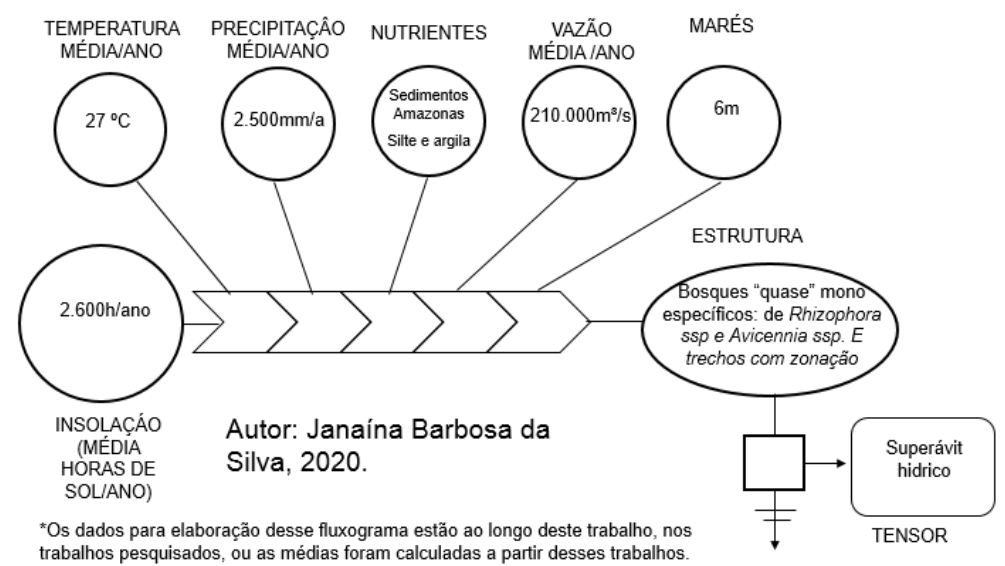

Figura 4: Assinatura energética dos manguezais da Unidade II, do Cabo Norte - AP $\left(01^{\circ} 40^{\prime} \mathrm{N}\right)$ à Ponta Curuçá - PA $\left(00^{\circ} 36^{\prime} \mathrm{S}\right)$.

Unidade III: Da Ponta Curuçá - PA (00³6’ S) à Ponta Mangue Seco - MA ( $2^{\circ} 15^{\prime}$ S).

Segundo Funari e Tarifa (2017), a insolação média anual é de $2.400 \mathrm{~h} / \mathrm{Sol} / \mathrm{ano}$. Esta Unidade está totalmente inserida na Região hidrográfica costa atlântica nordeste oriental. De acordo com a MMA (2006), El-Robrini et al. (2020), Andrade et al. (2018) e Schaeffer-Novelli et al. (1990), o clima é tropical quente e úmido, com um período chuvoso (MAM) que reduz a insolação, e outro seco (SON) que favorece o aumento da evapotranspiração em decorrência do aumento da insolação, com precipitação média anual de $1.823 \mathrm{~mm}$ e temperatura média de $27^{\circ} \mathrm{C}$. Apresenta um litoral formado por baías flúvioestuarinas, de vales fluviais afogados, configurando "falsas rias" dominadas por manguezais, altamente trabalhados por macro e mesomarés que registram amplitude média de $6 \mathrm{~m}$. Os sedimentos são areno-lamosos, decorrente da ação dos ventos, das ondas e das correntes de deriva litorânea resultando em um litoral bastante complexo, com trechos de erosão e outros de progradação e da deposição litorânea.

De acordo com Santos e Leal (2013), a vazão dos rios aolongo de todo o anoé perene, mas que pode estar diminuindo em decorrência dos conflitos de usos e impactos ambientais, desde abastecimento urbano, irrigação até a geração de energia, como retirada da vegetação para conversão das terras em áreas de moradias e vias de circulação. Assim, a assinatura energética, estrutura e tensor estão dispostas na Figura 4. A geografia desta Unidade favorece a presença dos mangues em suas reentrâncias, tendo sido registradas as ocorrências de Laguncularia racemosa, Avicennia germinans, A. schaueriana e Rhizophora mangle (Schaeffer-Novelli, 1989; Abreu et al., 2016; Senna e Bastos, 2009). Schaeffer-Novelli (1989) ressalta que as árvores de Rhizophora atingem $20 \mathrm{~m}$ nas franjas externas, enquanto Avicennia e Laguncularia dominam as áreas de terrenos mais elevados.

Um exemplo típico das características da Assinatura Energética para essa Unidade é a presença, na península de Ajuruteua, de bosques anões monoespecíficos de $A$. germinans (menor que $2,5 \mathrm{~m}$ ), em decorrência de elevada salinidade como resposta à baixa frequência de inundação (menor que 28 dias por ano). Onde o período de inundaçãoé mais regular, os bosques são mistos e a altura média é de $12 \mathrm{~m}$, com presença das espécies $R$. mangle, A. germinans e L. racemosa (Menezes, Berguer e Mehlig, 2008). Assim, para a assinatura energética da Unidade III tem-se que a estrutura de zonação encontrada nos bosques de mangue é decorrente da salinidade, essa é uma resposta das marés e de sua formação de costa, o que pode favorecer a presença de bosques anões (Figura 5). 
Revista Brasileira de Geografia Física v.014, n.04 (2021) 2286-2303.

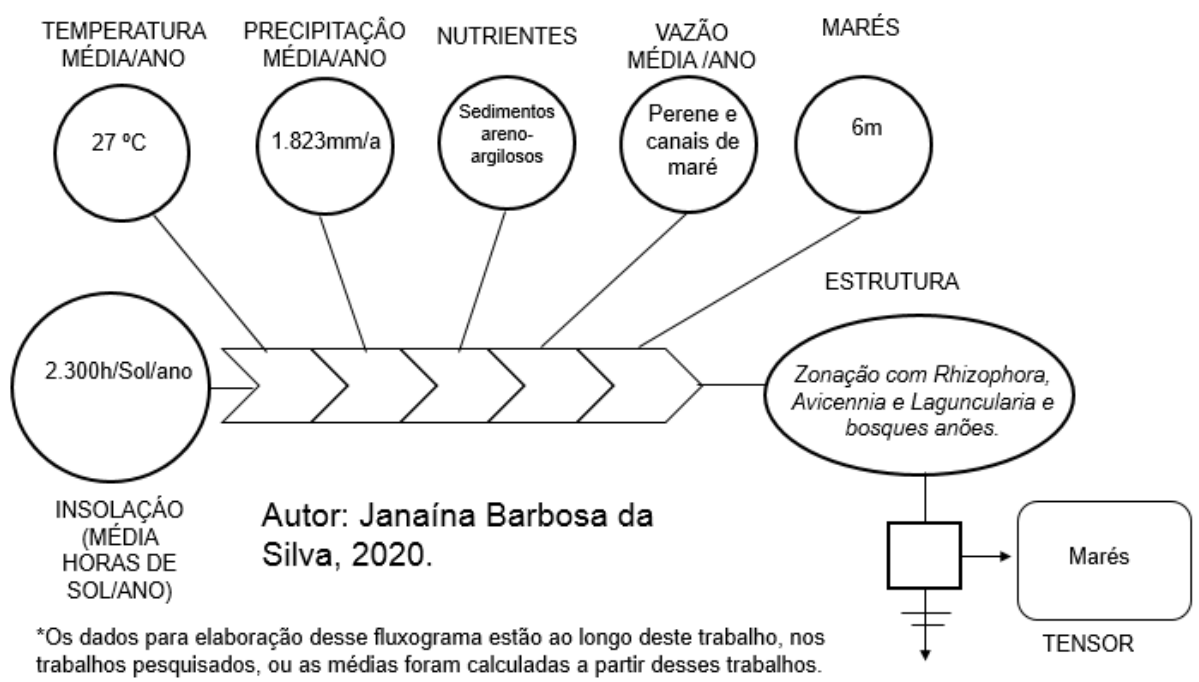

Figura 5: Assinatura energéticados manguezais da Unidade III: Ponta Curuçá - PA (00³6’ S) à Ponta Mangue Seco - MA $\left(2^{\circ} 15^{\prime} \mathrm{S}\right)$.

Unidade IV: Da Ponta do Mangue Seco - MA $\left(2^{\circ} 15^{\prime} \mathrm{S}\right)$ até Ponta Grossa (Icapuí-CE $\left.-2^{\circ} 50 ’ \mathrm{~S}\right)$. (Anteriormente essa Unidade se estendia da Ponta do Mangue Seco - MA $\left(2^{\circ} 15^{\prime}\right.$ S) ao Cabo Calcanhar - RN $\left(05^{\circ} 08^{\prime} \mathrm{S}\right)$.

Segundo Diniz e Oliveira (2016, p.577), esse trecho "... se destaca pelo seu maior aporte sedimentar e de água doce que chega ao mar. Isso se deve, principalmente, à dinâmica de descarga do Parnaíba". De acordo com Funari e Tarifa (2017), a insolação média é de $2.800 \mathrm{~h} / \mathrm{Sol} / \mathrm{ano}$, e segundo a Climate-Data (2020), a temperatura média é de $27^{\circ} \mathrm{C}$ e precipitação de $1700 \mathrm{~mm} / \mathrm{ano}$; a média da maré máxima, de acordo com Tessler e Goya (2005), é de 4m; os principais contributivos ao aporte hídrico nesse trecho são os Rios Parnaiba, com uma vazão de $776 \mathrm{~m}^{3}$. $\mathrm{s}^{-1}$ controlada pela hidrelétrica de Boa Esperança, Rio Anil em São
Luiz, com $1,1 \mathrm{~m}^{3} \cdot \mathrm{s}^{-1}$, equilibrada durante o ano inteiro (MMA, 2006; PENEREIRO e ORLANDO, 2013).

Nos estados do Maranhão, Piauí e Ceará, inseridos nessa Unidade, tem-se a presença de: $A$. schaueriana, $R$. mangle, $R$. harrisonii, $R$. racemosa e Laguncularia racemosa (ABREU et al., 2016; GONÇALVES et al., 2018; NASCIMENTO E SASSI, 2001; CASTRO, MORO e MENESES, 2012); QUEIROZ e NUNES, 2001; IRVING, OLIVEIRA e LIMA, 1988). Apesar da perenidade dos rios nessa Unidade, os períodos de seca acabam por diminuir o volume caudal, que também é impactado pela elevada evapotranspiração decorrente de mais de 2.700 horas de Sol-ano, aliada a uma amplitude de maré de $4 \mathrm{~m}$, favorecendo a presença de zonação das espécies de mangue nas áreas de Foz em decorrência da variação da salinidade (Figura 6).

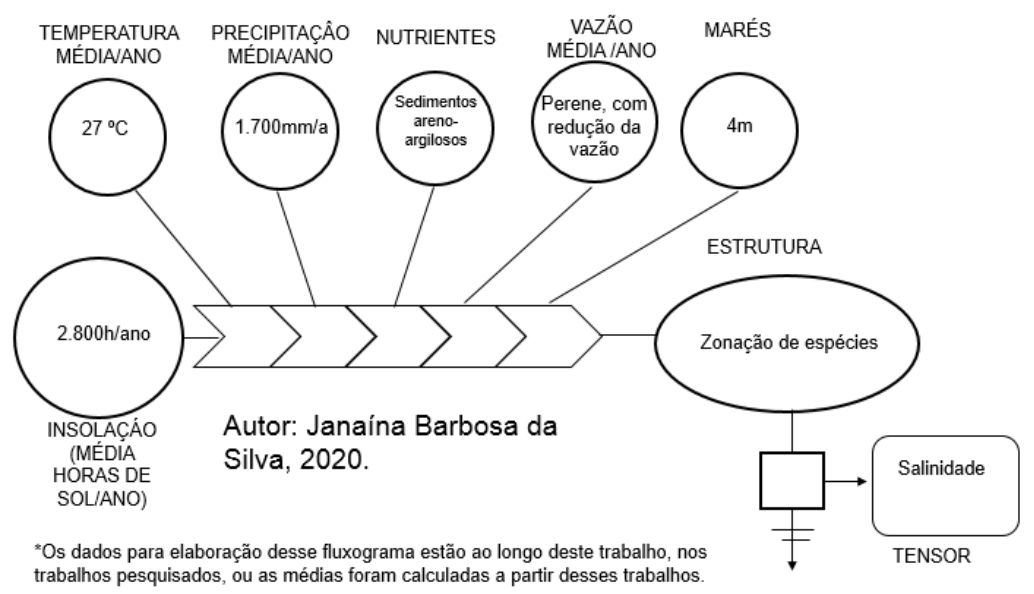

Figura 6: Assinatura energética dos manguezais da Unidade IV: Da Ponta do Mangue Seco - MA (2¹5’ S) até Ponta Grossa (Icapuí-CE - 250’S). 
Unidade V: Da Ponta Grossa em Icapuí-CE ( $\left.{ }^{\circ} 50^{\prime} \mathrm{S}\right)$ até Cabo Calcanhar - $\mathrm{RN}\left(05^{\circ} 08^{\prime} \mathrm{S}\right)$. (Anteriormente esse trecho estava inserido na Unidade IV).

A insolação apresenta a mínima de 2.400 e máxima de 3.200 horas de Sol (média de $3.000 \mathrm{~h} / \mathrm{Sol} / \mathrm{ano}$ ), típico de ambiente semiárido. A média da temperatura é de $26,8^{\circ} \mathrm{C}$ e a precipitação, com 537,6 mm/ano, ocorre basicamente em três meses (abril, maioe junho). Quanto à vazão, os rios apresentam déficit hídrico devido aos regimes de precipitação e os inúmeros represamentos ao longo das bacias, e a oferta de água doce mais regular ocorre por áreas de dunas. Essa Unidade apresenta rios intermitentes na maior parte de seu curso (alto e médio), e barramentos e usos múltiplos de suas águas, onde os manguezais sobrevivem a uma salinidade elevadíssima, que por vezes ultrapassa a do oceano em até $50 \%$. Tais valores são decorrentes da elevada evaporação e valores negativos de água doce, resultando em uma salinidade desde salobra, com salinidade aproximada a $10 \mathrm{~g} . \mathrm{L}^{-1}$; solução salina com aproximadamente $30 \mathrm{~g} . \mathrm{L}^{-1}$ e níveis hipersalinos maior que $50 \mathrm{~g} . \mathrm{L}^{-1}$, favorecendo assim a presença de extensas planícies hipersalinas (apicuns) sem qualquer tipo vegetacional. A amplitude de maré máxima é de 4m. (Diniz e Pereira, 2015; Diniz e Oliveira 2016; Funari e Tarifa, 2017; Vital, 2020; CPRM, 2005; Medeiros et al., 2010).

Para esta unidade foram referidas as espécies Avicennia germinans, A. schaueriana, Laguncularia racemosa, Rhizophora mangle, $R$. racemosa (Costa, Rocha e Cestaro, 2014; Fernandes et al., 2017; Silva e Silva, 2019; Fernandes et al., 2018; Guedes, Santos e Cestaro, 2016). Quanto à assinatura energética desta Unidade, tem-se um ambiente altamente estressado do ponto de vista hídrico, com rios intermitentes, elevadas taxas de evapotranspiração, baix os teores de nutrientes e marés que favorecem ainda mais o aumento e a manutenção de elevados valores de salinidade. Todos esses fatores refletem na estrutura do manguezal com a presença dos apicuns e bosques de mangues com alturas baixas e a presença maciça de espécie mais tolerante ao sal (Figura 7) como é o caso da A. germinans.

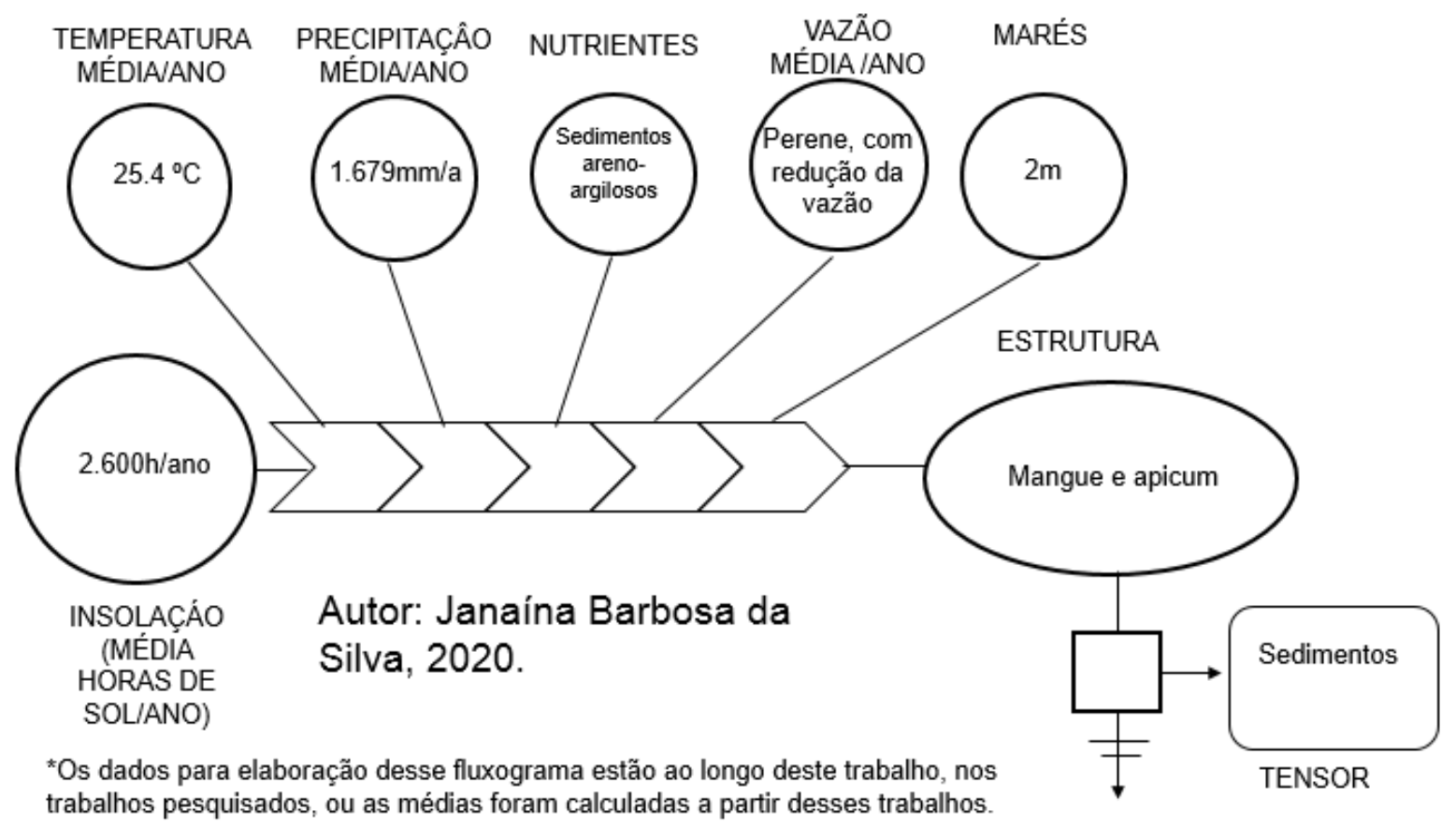

Figura 7: Assinatura energética dos manguezais na Unidade IV: Ponta do Mangue Seco - MA $\left(2^{\circ} 15^{\prime} \mathrm{S}\right)$ ao Cabo Calcanhar - $\mathrm{RN}\left(05^{\circ} 08^{\prime} \mathrm{S}\right)$.

Unidade VI: Do Cabo Calcanhar - RN $\left(05^{\circ} 08^{\prime} \mathrm{S}\right)$ ao Recôncavo Baiano - BA (13º0’ S);

Nessa Unidade a insolação média anual é de 2.600h/ano (Funari e TarifA, 2017), a temperatura média é de $25.4^{\circ} \mathrm{C}$ e precipitação média anual de $1.679 \mathrm{~mm} / \mathrm{a}$ (esses valores correspondem às médias de temperatura e precipitação de todas as capitais dessa Unidade a partir do CLIMATE-DATA, 2020). Os rios apresentam baixa vazão e respectivas descargas sólidas; a linha costeira apresenta recifes de 
Revista Brasileira de Geografia Física v.014, n.04 (2021) 2286-2303.

arenitos que amortecem as ondas, que contribuem também com baixa descarga sólida, logo os nutrientes são a própria matéria orgânica produzida pela serapilheira das árvores de mangue e oriundo da Formação Barreiras e sedimentos de origem marinha (Vila Nova, Torres e Coelho, 2017; Araújo et al., 2019). Quanto à amplitude de maré tem-se o valor médio de $2 \mathrm{~m}$ para a Unidade (Diniz e Oliveira, 2016). A vegetação de mangue se desenvolve principalmente em áreas abrigadas das ondas em estuários. A altura das árvores varia entre 10 a $20 \mathrm{~m}$ (Schaeffer-Novelli, 1990).
As espécies encontradas são $R$. mangle, $L$ racemosa e Avicennia ssp. (Silva, 2012; Silva, Silva e Araújo, 2020; Vila Nova, Torres e Coelho, 2017), sendo possível encontrar áreas de apicuns/planícies hipersalinas em diversos Estados. O Apicum é uma feição pulsante que responde às dinâmicas naturais, possibilitando sua expansão em tempos favoráveis, bem como sua retração, originando novas áreas de apicuns, mas também como uma resposta às condicionantes de maré e vazão hídrica fluvial (Figura 8).

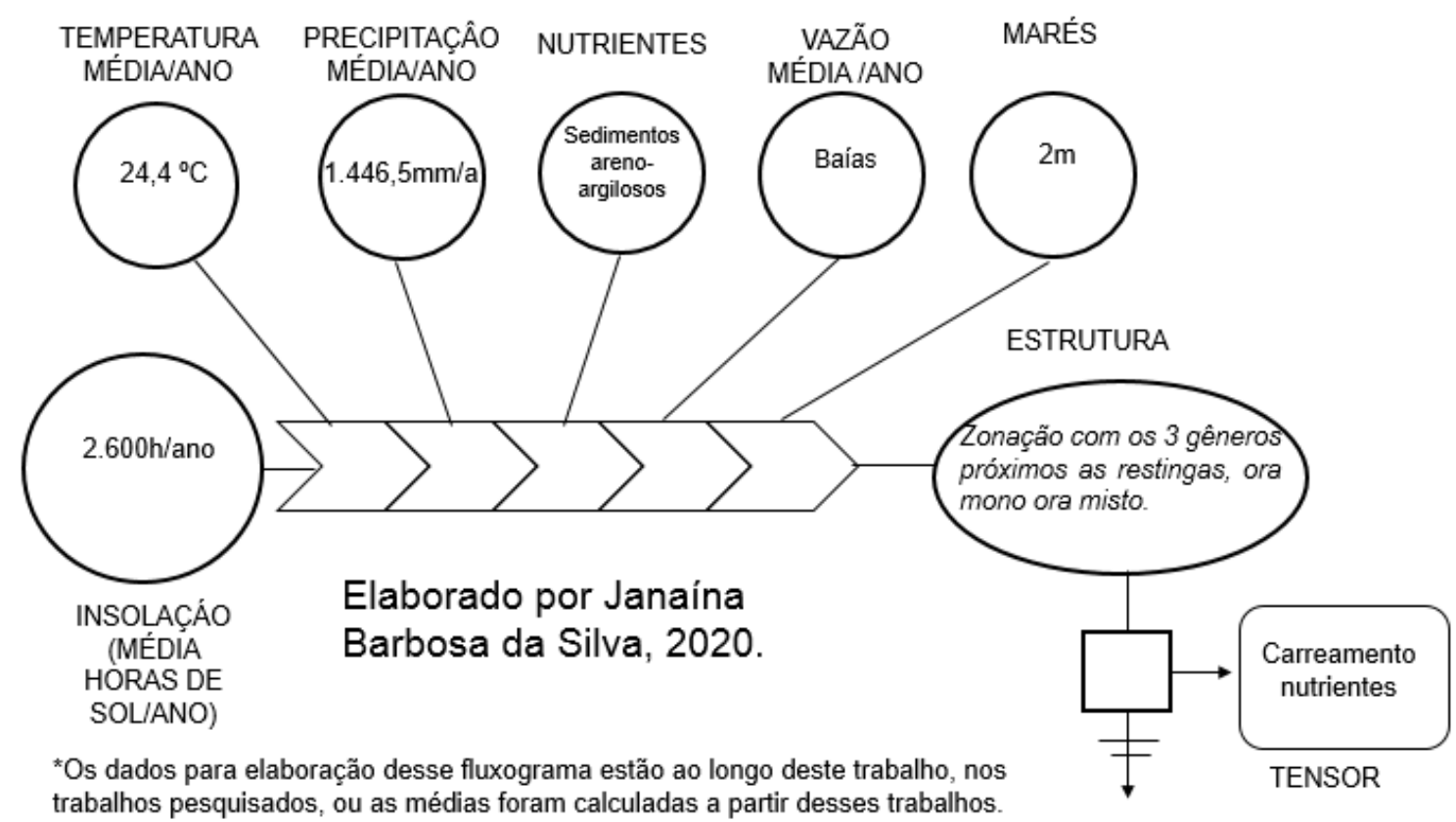

Figura 8: Assinatura energética dos manguezais da Unidade VI: Do Cabo Calcanhar - RN $\left(05^{\circ} 08^{\prime}\right.$ S) ao

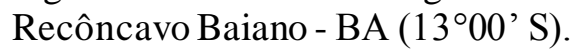

Unidade VII: Do Recôncavo Baiano - BA $\left(13^{\circ} 00^{\prime} \mathrm{S}\right)$ ao Cabo Frio - RJ $\left(23^{\circ} 00^{\prime} \mathrm{S}\right)$

A insolação nessa Unidade tem uma média de 2.600 dias de Sol ao ano; a precipitação média é de $1.446,5 \mathrm{~mm} /$ ano e temperatura de $24.4^{\circ} \mathrm{C}$ (média para as capitais). Os sedimentos e nutrientes são de origem fluvial, uma vez que há uma significativa contribuição hídrica oriunda de rios caudalosos como os rios Contas, Pardo, Jequitinhonha, Doce, Itabapoana e Paraíba do Sul, responsáveis pelas planícies costeiras. Pouco determinante nessa construção deposicional é a amplitude de maré que para esse setor é $\leq$ a $2 \mathrm{~m}$. Restingas são abundantes, geralmente ocorrem bordeando os manguezais ou paralelas a eles (Tarifa e Funari, 2016; Tessler e Goya 2005,) (Figura 9). 
Revista Brasileira de Geografia Física v.014, n.04 (2021) 2286-2303.

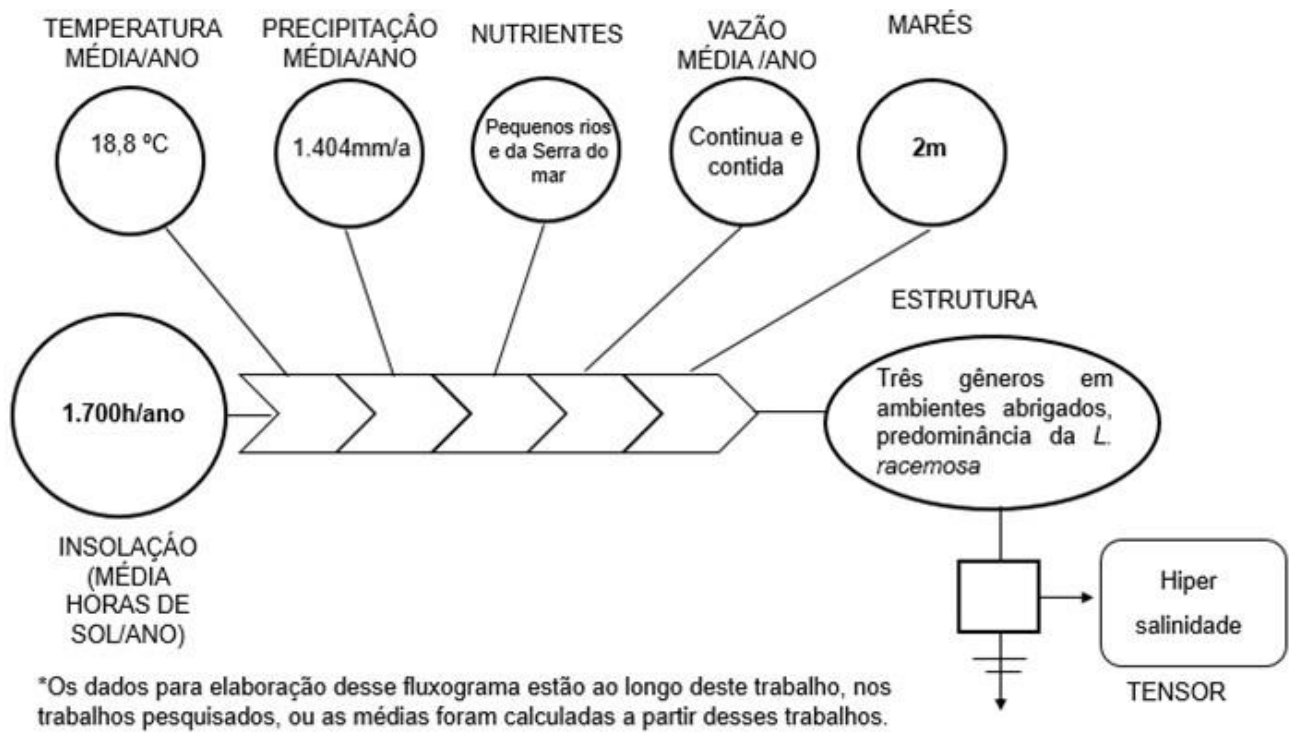

Figura 9: Assinatura energética dos manguezais da Unidade VII, Recôncavo Baiano - BA $\left(13^{\circ} 00^{\prime}\right.$ S) ao Cabo Frio - RJ (230’ S).

Os estados inseridos nessa Unidade são Sul da Bahia, Espírito Santo e Norte do Rio de Janeiro. As espécies encontradas foram: $L$. racemosa, $R$. mangle $e$ A. germinans. Os bosques são organizados em padrões de zonação, com altura máxima registrada de 20m (Cuzzuol e Campos, 2001; Soares et al., 2008; Souza et al., 1996; Martins, Couto e Delabie, 2011; Bernini e Rezende, 2004; Bernini et al., 2014; Soares, 1999).

Unidade VIII: Do Cabo Frio - RJ $\left(23^{\circ} 00^{\prime} \mathrm{S}\right)$ à Torres -RS $\left(29^{\circ} 20^{\prime} \mathrm{S}\right)$

A insolação nessa Unidade tem uma média de $1.700 \mathrm{~h} / \mathrm{Sol} / \mathrm{ano}$ (Tarifa e Funari, 2016), com maiores ocorrências de drenagens endorréicas, a contribuição fluvial não é expressiva, sendo os contributivos significativos os rios Ribeira de Iguape e o Itajaí-Açú. Os sedimentos são oriundos da Serra do Mar (cristalino), com trechos de extensas planícies costeiras, ou com a Serra tocando a linha de costa, e presença de baías. As marés são de $2 \mathrm{~m}$, trabalhadas pela geomorfologia $\mathrm{e}$ podendo criar verdadeiras correntes de maré (Tessler e Goya, 2005). A temperatura média/ano é de $18,8^{\circ} \mathrm{C}$ e precipitação média/ano de $1.404 \mathrm{~mm} / \mathrm{ano}$ (CLIMATE-DATA, 2020). Na Figura 10 tem-se a Assinatura energética para a Unidade VIII.

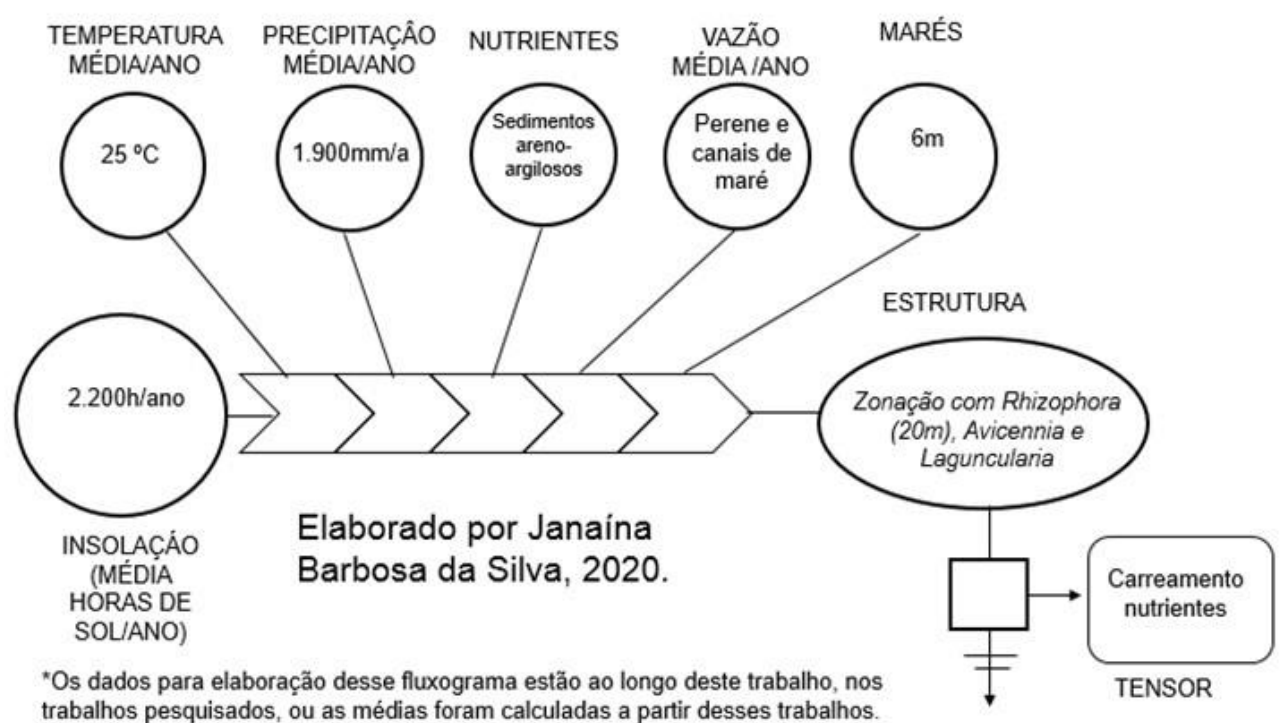

Figura 10: Assinatura energética dos manguezais da Unidade VIII, Cabo Frio - RJ ( $23^{\circ} 00^{\prime}$ S) a Torres -RS $\left(29^{\circ} 20^{\prime} \mathrm{S}\right)$ 
Na Unidade VIII ocorre o limite latitudinal de dispersão de espécies de mangue, mais precisamente no estado de Santa Catarina, com registro de $R$. mangle aos $27^{\circ} 30^{\prime} \mathrm{S}$ e para a $A$. schaueriana e L. racemosa aos $28^{\circ} 30^{\prime} \mathrm{S}$ (SchaefferNovelli, 1989). Há manguezais bem tensionados devido à pressão urbana, zonação e diversidade de porte e densidade, áreas com baixa diversidade (Pellegrini, 2000; Canesin Bellido e Bellido, 2020; Lardosa, Simões e Soares 2013; Cunha-Lingnon, 2001; Menguini, 2008; Souza Sobrinho, Bresolin e Klein, 1969; Froidefond e Soriano-Sierra, 1996; Vargas et al., 2011).

Unidade IX: De Torres - RS (29²0' S) ao Chuí $\operatorname{RS}\left(33^{\circ} 45^{\prime} \mathrm{S}\right)$.

A insolação média ao ano é de 2.300h/sol/ano (Tarifa e Funari, 2016). A precipitação média ao ano é de $1.172 \mathrm{~mm}$, enquanto a temperatura média anual é de $16,8^{\circ} \mathrm{C}$ (CLIMATE-DATAd, 2020). Os sedimentos são arenosos finos em dunas, praias e pontais numa costa retilínea com presença de lagunas, trabalhadas por micromarés de $2 \mathrm{~m}$. A drenagem fluvial é insignificativa, exceto pela Laguna dos Patos (Tessler e Goya, 2005). A assinatura energética dessaUnidade impossibilita a existência de espécies de mangue, sendo a baixa temperatura o principal tensor, favorecendo assim a presença das marismas, ecossistema análogo aos manguezais nas altas latitudes. Na Figura 11 está representada a Assinatura energética para essa Unidade (IX).

De acordo com Costa e Marangoni (2000) e Silva, Silva e Araújo (2020), as marismas são importantes nas regiões subtropicais, também inundadas por água salgadas regularmente. Sua vegetação é predominantementeherbácea, sendo as mais comuns Spartina densiflora Brong, Hydrocotyle bonariensis Lam., Cyperus obtusatus (Presl) Mattf. \& Kük. e Bacopa monnieri (L.) Wettst. A partir de Laguna, em Santa Catarina, esse ecossistema se torna mais abundante, uma vez que suporta baixas temperaturas tanto da água quanto do ar.

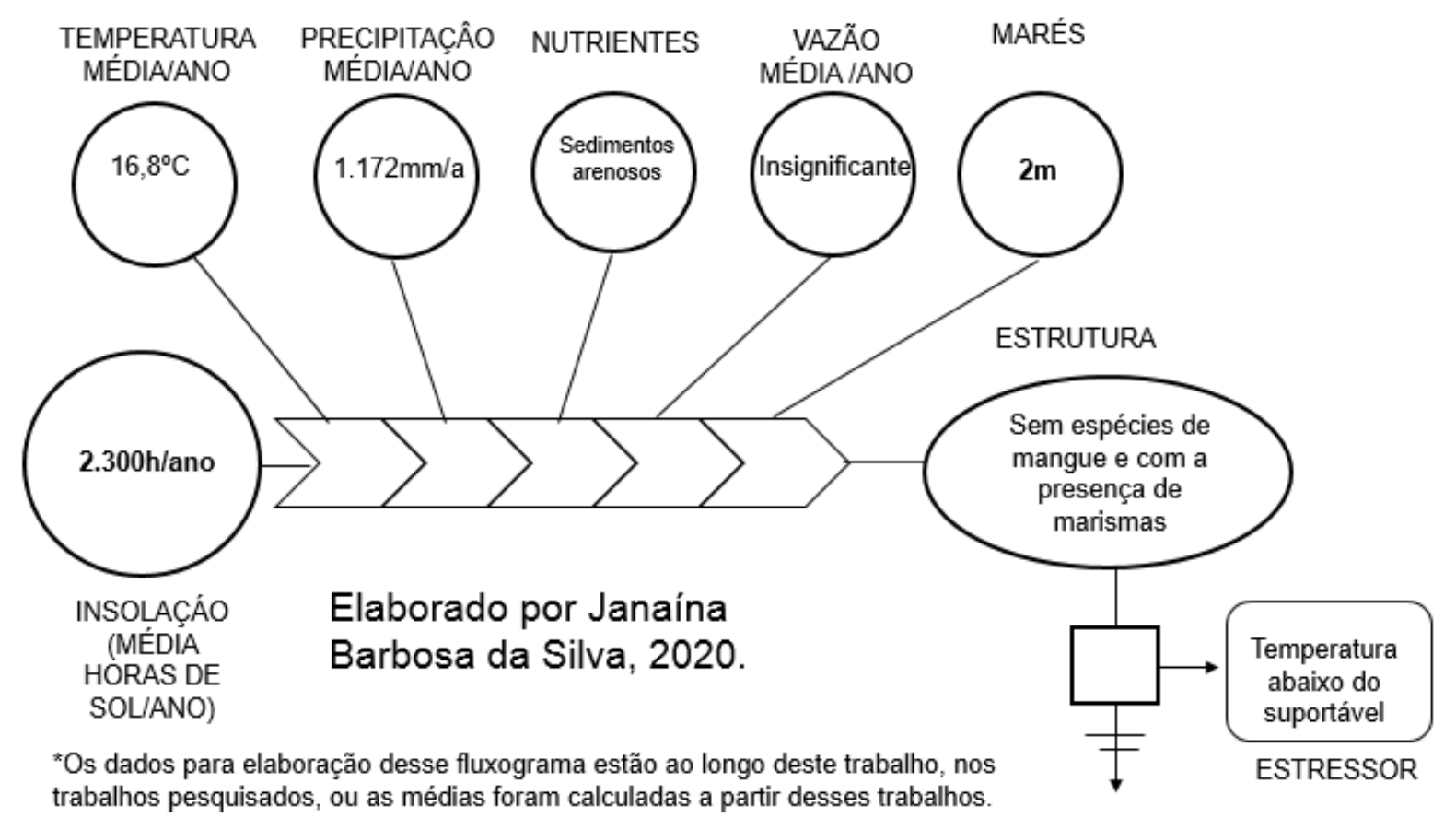

Figura 11: Assinatura energética da Unidade IX, Torres - RS (29²0’ S) ao Chuí - RS (3345’ S).

A partir das análises da presença e dispersão da vegetação de mangue, foi possível identificar que para o Brasil o gênero de maior diversidade é Rhizophora, esse ocorre em toda a costa brasileira. Contudo, somente a Rhizophora mangle está presente desde a foz do Rio Oiapoque-AM até Santa Catarina. A R. racemosa e $R$. harrisonii se dispersam desde a Região Norte com seu limite sul no Delta do Rio Parnaíba-PI no Nordeste brasileiro. 
Revista Brasileira de Geografia Física v.014, n.04 (2021) 2286-2303.

\section{Conclusão}

Foram identificadas nove Unidades Ambientais para o Domínio Costeiro brasileiro, com base em suas características gerais, onde estudo anterior estabelecia oito Unidades.

Os bosques mais extensos estão nas Unidades I, II e III, abrangendo todo o litoral da Região Norte e o Estado do Maranhão, este pertencente à Região Nordeste. Tais Unidades apresentam características semelhantes quanto às energias subsidiárias que estão diretamente associadas à climatologia, principalmente a vazão e aporte hídrico com diferenças marcantes.

Como resposta à Assinatura Energética de cada unidade, foi possível identificar padrões de dispersão/ocorrência de espécies de mangue, onde as Unidades I e II apresenta maior diversidade de espécies com padrões de bosques monoespecíficos, sendo a amplitude de maré e o superávit hídrico identificados como os tensores respectivamente. Nas Unidades III e IV aparecem padrões de zonação das espécies de mangue, onde os tensores são amplitude de maré e a salinidade, respectivamente. Para as Unidades V e VI a feição mangue e apicum são comuns, onde a hipersalinidade é o tensor da primeira, enquanto da segunda é a deposição de sedimentos. Para a Unidade VII tem-se que a vegetação de mangue ocorre bordeando e ou sendo margeada pelo ecossistema Restinga, onde o fator tensor é o carreamento de nutrientes. A Unidade VIII apresenta as mesmas características da anterior, contudo as restingas não mais aparecem. Por fim, a Unidade IX, devido às baix as temperaturas atuando como tensor, acaba por não favorecer a ocorrência de mangue, mas sim de um ecossistema análogo denominado de marismas.

Para o Brasil o gênero de maior diversidade é Rhizophora, ocorrendo em toda a costa brasileira. Contudo, somente $R$. mangle está presente desde a foz do Rio Oiapoque-AM até Santa Catarina, enquanto $R$. racemosa e $R$. harrisonii se distribuem desde a Região Norte até o Delta do Rio Parnaíba-PI no Nordeste brasileiro.

\section{Agradecimentos}

A Universidade Federal de Campina Grande, e seu programa de incentivo de qualificação de docentes;

Ao programa de pós-graduação em Geografia da Universidade Federal de Pernambuco, onde foi desenvolvido o pósdoutorado (2019/20);

A professora Yara Schaeffer-Novelli, inspiração ao estudo dos manguezais, que em 2008 ao ministrar a disciplina IOB 5721-3 "O ambiente biológico dos manguezais" na Universidade se São Paulo-USP me incentivou a elaborar esse artigo.

\section{Referências}

Abreu, M. M. O.; Veiga, N.; Costa-Neto, S. V.; Fernandes, M. E. Vegetação Arbórea: Distribuição Espacial. In Os Manguezais da Costa Norte Brasileira Vol. III/ organizador: Marcus Emanuel Barroncas Fernandes. Bragança: Laboratório de Ecologia de Manguezal, 2016. 175 p.: il. Disponível em https://livroaberto.ufpa.br/jspui/handle/prefi $\underline{\mathrm{x} / 635}$. Acesso em 11/09/2019

Agência Nacional De Águas - ANA. Panorama da qualidade das águas superficiais do Brasil: 2012/Agência Nacional de Águas Brasília: ANA, 2012. Disponível em http://arquivos.ana.gov.br/imprensa/publica coes/Panorama_Qualidade_Aguas_Superfic iais_BR_2012.pdf. Acesso em 11/09/2019.

Andrade, M. M. N. De; Souza-Filho, P. W. M.; Szlafsztein, C. F. Sensibilidade Ambiental a Derramamento de Óleo e Mapeamento de Unidades de Paisagem na Região Portuária do Maranhão. Journal of Integrated Coastal Zone Management / Revista de Gestão Costeira Integrada 18(2):73-84 (2018). Disponível em https://www.aprh.pt/rgci/pdf/rgcin65_Andrade.pdf. Acesso em 17/06/2019.

Araújo, E. D. S., Silva, J. B., Oliveira, T. S., Santana, N. M. G., F. Freire, M. B. G. Apicum do estuário de Barra de GramamePB: Análises físicas e químicas. Revista Brasileira de Geografia Física v.12, n.01 (2019) 112-123. Disponível em: https://www.researchgate.net/profile/Elania Daniele_Araujo/publication/333857857 Apicum_do_estuario_de_Barra_de_Grama me-

$\overline{\mathrm{PB}}$ Analises_fisicas_e quimicas/links $/ 5 \mathrm{~d} 8$ 10009a6fdcc12cb96f551/Apicum-doestuario-de-Barra-de-Gramame-PB-

Analises-fisicas-e-quimicas.pdf. Acesso em 12/12/2019.

Banerjee, L. K. Influence of salinity on mangrove zonation. Botanical Survey of India, Howrah - 7[[103, India H. Lieth and A. Al Masoom (eds): Towards the rational use of high salinity tolerant plants, Vol. J: 181-186. 1993 Kluwer Academic Publishers. Disponível em 
Revista Brasileira de Geografia Física v.014, n.04 (2021) 2286-2303.

https://link.springer.com/chapter/10.1007/9

78-94-011-1858-3_19. Acesso em 17/06/2019.

Bernini, E.; Santos, C. De F. N. R. Dos; Pinto, F. L.; Rezende, C. E. Fitossociologia de florestas de mangue plantadas e naturais no estuário do Rio das Ostras, Rio de Janeiro, Brasil. v. 27, n. 1 (2014). Disponível em: https://periodicos.ufsc.br/index.php/biotem as/article/view/29390. Acesso em 04/06/2019.

Bernini, E.; Rezende, C. E. Estrutura da vegetação em florestas de mangue do estuário do rio Paraíba do Sul, Estado do Rio de Janeiro, Brasil. Acta Bot. Brasil. 18(3):491-502. 2004. Disponível em: http://www.scielo.br/scielo.php?pid=S0102

33062004000300009\&script=sci_abstract\& thlng=pt Acesso em: 13/05/2019.

BRASIL. Ministério Do Meio Ambiente, Caderno da Região Hidrográfica Atlântico Nordeste Ocidental / Ministério do Meio Ambiente, Secretaria de Recursos Hídricos. - Brasília: MMA, 2006. Disponível em https://www.mma.gov.br/estruturas/161/_p ublicacao/161_publicacao03032011024629 .pdf Acesso 02/01/2020.

Canesin, F. P.; Bellido Jr. A. V.; Bellido, L. F. Comportamento cinético do manganês numa floresta de manguezal-itacuruçá, rj. Disponível em: https://www.ipen.br/biblioteca/cd/inac/200 2/ENAN/E03/E03_358.PDF. Acesso em 13/04/2020.

Carvalho, M. A. G.; Jardim, E. A. Composição e estrutura florística em bosques de manguezais paraenses, Brasil. Ciência Florestal, Santa Maria, v. 27, n. 3, p. 923930, jul.-set., 2017. Disponível em https://periodicos.ufsm.br/cienciaflorestal/a rticle/view/28641. Acesso em 20/06/2020.

CLIMATE-DATAa Amapá. Disponível em https://pt.climate-data.org/america-dosul/brasil/amapa/amapa-274627/ Acesso 16/01/2020.

CLIMATE-DATAb Maranhão Disponível em https://pt.climate-data.org/america-dosul/brasil/maranhao/central-do-maranhao313648/ Acesso 16/01/2020.

CLIMATE-DATAd Rio Grande de Sul. Disponível em https://pt.climate- data.org/america-do-sul/brasil/rio-grandedo-sul-187/ Acesso 16/01/2020.

CPRM - Serviço Geológico do Brasil Projeto cadastro de fontes de abastecimento por água subterrânea. Diagnóstico do município de Guamaré, estad o do Rio Grande do Norte / Organizado [por] João de Castro Mascarenhas, Breno Augusto Beltrão, Luiz Carlos de Souza Junior, Saulo de Tarso Monteiro Pires, Dunaldson Eliezer Guedes Alcoforado da Rocha, Valdecílio Galvão Duarte de Carvalho. Recife: CPRM/PRODEEM, 2005. Disponível em http://rigeo.cprm.gov.br/xmlui/bitstream/ha ndle/doc/16968/rel_guamare.pdf?sequence $=1$. Acesso em 16/06/2019.

Costa, D. F. S.; Rocha, R. M.; Cestaro, L. A. Análise fitoecológica e zonação de manguezal em estuário hipersalino. Mercator, Fortaleza, v. 13, n. 1, p. 119-126, jan./abr. 2014. Disponível em http://www.scielo.br/scielo.php?pid=S1984 $=$ $\overline{2} 2012014000100119 \&$ script $=$ sci_abstract\& tlng=pt. Acesso em 15/06/2019.

Costa, C. S. B.; Marangoni, J. C. Impacto ambiental do asfaltamento da BR 101 sobre as marismas de São José do Norte (RS, Brasil): Estado atual e efeitos potenciais. Annals of V Simpósio de Ecossistemas Brasileiros. 10-15 October 2000. Volume I. Publicação ACIESP n. 109- I. São Paulo, ACIESP, 268-291. Disponível em http://www.repositorio.furg.br/bitstream/ha ndle/1/3125/Impacto\%20ambiental\%20do

\%20asfaltamento\%20da\%20BR101\%20sob re\%20as\%20marismas\%20de\%20S\%c3\%a $30 \% 20 \mathrm{Jos} \%$ c3\%a9\%20do\%20Norte $\% 20 \%$ 28RS\%2c\%20Brasil\%29\%20Estado\%20at ual\%20efeitos\%20potenciais.pdf?sequence $=1$. Acesso em 15/06/2019.

Cuzzuol, G. R. F.; Campos, A. Aspectos nutricionais na vegetação de manguezal do estuário do Rio Mucuri, Bahia, Brasil. Rev. bras. Bot. vol.24 no.2 São Paulo June 2001. Disponível

em http://www.scielo.br/scielo.php?pid=S0100 $\underline{-84042001000200013 \& \text { script }=\text { sci_arttext }}$ Acesso em 02/03/2020.

Diniz, M. T. M.; Pereira, V. H. C. Climatologia do estado do Rio Grande Do Norte, Brasil: sistemas atmosféricos atuantes e 
Revista Brasileira de Geografia Física v.014, n.04 (2021) 2286-2303.

mapeamento de tipos de clima. Bol. Goia. Geogr. (Online). Goiânia, v. 35, n. 3, p. 488506, set./dez. 2015. Disponível em https://webcache.googleusercontent.com/se arch?q=cache:UJCgAaK7Yt4J:https://www .revistas.ufg.br/bgg/article/download/38839 $/ 19692 /+\& \mathrm{~cd}=3 \& \mathrm{hl}=\mathrm{pt}-$

BR\&ct=clnk\&gl=br.$\quad$ Acesso em 28/06/2019.

Diniz, M. T. M.; Oliveira, G. P. Proposta de compartimentação em mesoescala para o litoral do Nordeste brasileiro. Rev. Bras. Geomorfol. (Online), São Paulo, v.17, n.3, (Jul-Set) p.565-590, 2016. Disponível em http://www.lsie.unb.br/rbg/index.php/rbg/ar ticle/view/844/552 . Acesso em

El-Robrini, M.; Silva, M. M. A.; Souza Filho, P. W. M. E.; El-Robrini, M. H. S.; Silva Jr., O. G.; França, C.F. Erosão e prograd ação do litoral brasileiro-Pará. Disponível em https://www.mma.gov.br/estruturas/sqa_sig ercom/_arquivos/pa_erosao.pdf. Acesso em 21/02/2020.

El-Robrini, M.; Marques J., Valter; Silva, Marcelo Moreno A. Da; El-Robrini, M. Helena S.; Feitosa, Antonio Cordeiro; Tarouco, José Edgar Freitas; Santos, Jorge Hamilton S. Dos; Viana, Janilson Rosa. Erosão e progradação do litoral brasileiro | Maranhão. Disponível em https://www.mma.gov.br/estruturas/sqa_sig ercom/arquivos/ma_erosao.pdf. Acesso em 25/02/2020.

Fernandes, R. T. V.; Fernandes, R. T. V.; Pinto, A. R. M.; Oliveira, J. F. ; Melo, A. S.; Marinho, J. B. M. Ocorrência De Brassolis Sp. Em Manguezais À Margem Do Estuário Do Rio Apodi-Mossoró, Rio Grande Do Norte Revista Verde, V.12, N.3, P.617-621, $2017 . \quad$ Disponível Em: Https://Dialnet.Unirioja.Es/Servlet/Articulo ?Codigo=7158438. Acesso Em 21/01/2020.

Fernandes, R. T. V.; Oliveira, J. F.; Fernandes, R. T. V.; Pinto, A. R. M.; Nascimento, L.; Oliveira, J. C. D.; Novaes, J. L. C. Impact Of Carciniculture In Mangrove Of Rio Das Conchas, Porto Do Mangue, Rio Grande Do Norte. Soc. Nat. | Uberlândia, Mg | V.30 | N.3 | P.64-84 | Set./Dez. 2018. Disponível Em

Http://Www.Seer.Ufu.Br/Index.Php/Socied
adenatureza/Article/View/37257/Pdf Acesso Em 04/03/2020.

Fernandes, M. E. B., Nascimento, A. A. M.; Carvalho, M. L. Estimativa Da Produção Anual De Serapilheira Dos Bosques De Mangue No Furo Grande, Bragança-Pará. R. Árvore, Viçosa-Mg, V.31, N.5, P.949-958, 2007. Disponível Em Http://Www.Scielo.Br/Scielo.Php?Pid=S01 $\underline{00-}$

$\underline{67622007000500019 \& \text { Script }=\text { Sci_Abstract }}$ \&Tlng=Pt. Acesso Em 29/06/2019.

Froidefond, J. M. E Soriano-Sierra, J. Sensoriamento Remoto Sobre Ecossistemas De Manguezal Da Ilha De Santa Catarina, Brasil. I: Adequação Da Técnica. Anais Viii Simpósio Brasileiro De Sensoriamento Remoto, Salvador, Brasil, 14-19 Abril 1996, Inpe, P. 157-163. Disponível Em Http://Marte.Sid.Inpe.Br/Col/Sid.Inpe.Br/D eise/1999/01.27.15.47/Doc/T261.Pdf. Acesso Em 07/06/2019.

Funari, F. L.; Tarifa, J. R. Sunshine, Global Radiation And Net Radiation In Brazil. Revista Do Instituto Geológico, São Paulo, $38 \quad$ (2), 49-83, 2017. Http://Www.Ppegeo.Igc.Usp.Br/Index.Php/ Rig/Article/View/12153/11699 Acesso Em 05/08/2019. Acesso em 30/06/2019.

Gens F., Lessa G.C., Cirano M., Lima G.M.P. As tendências de longo prazo das vazões fluviais no litoral do Estado da Bahia. In: ABEQUA, Congresso sobre Planejamento e Gestão das Zonas Costeiras dos Países de Expressão Portuguesa, 9, Recife, Anais, 5p. (versão em CD), 2003.

Gonçalves, A. L.; Cruz, V. M. S.; Campos, J. R. P.; Souza, D. V. Composição Florística E Fitossociológica Do Manguezal Da Zona Portuária De São Luís, Maranhão, Brasil. Disponível em: BIOFIX Scientific Journal v. 3 n. 1 p. 01-07 2018. Acesso em 12/12/2019.

Guedes, D. R. Da C.; Santos, N. M; Cestaro, L. A. Planície flúvio-marinha do Rio Grande do Norte: uma abordagem geossistêmicas. Volume 2, Numero Especial. 2016. Disponível em https://periodicos.ufrn.br/revistad oregne/art icle/view/10530/7457. Acesso em 22/01/2020. 
Revista Brasileira de Geografia Física v.014, n.04 (2021) 2286-2303.

Lardosa, E. I.; Simões, M.; Soares, M. L. G. Cartografia das áreas de ocorrência de manguezais no estado do rio de janeiro através da integração de múltiplas fontes de dados. Revista Brasileira de Cartografia (2013) N0 65/1: 1-14. Disponível em https://www.alice.cnptia.embrapa.br/alice/ bitstream/doc/981343/1/cartografiadasare as.pdf Acesso em 14/06/2019.

Lugo, A. E.; Snedaker, S. C. The Ecology of Mangroves. Annual Review of Ecology and Systematics Vol. 5 (1974), pp. 39-64 (26 pages). Disponível em https://www.jstor.org/stable/2096879?seq= 1\#metadata_info_tab_contents Acesso em 20/06/2019.

Madi, A. P.L.M.; Boeger, M. R.T.; Reissmann, C. B. Composição química do solo e das folhas e a eficiência do uso de nutrientes pelas espécies de manguezal. Revista Brasileira de Engenharia Agrícola e Ambiental - Agriambi. 2015, vol. 19 Edição 5, página 433-438. 6p.

Martins, P. T. A.; Couto, E. C. G.; Delabie, J. H. C. Fitossociologia e estrutura vegetal do Manguezal do rio Cururupe (Ilhéus, Bahia, Brasil). Revista da Gestão Costeira Integrada 11(2):163-169 (2011). Disponível em

https://www.redalyc.org/pdf/3883/3883401 33002.pdf. Acesso em 06/06/2019.

Nascimento, M. S. V.; Sassi, R. Interferências humanas na área de influência direta do manguezal dos rios Timonha/Ubatuba, estado do Piauí, Brasil. Revista Nordestina de Biologia, 15(2): 73-90 15.xii.2001. Disponível em

https://www.researchgate.net/profile/Robe rto Sassi3/publication/31515200 INTERFE RENCIAS HUMANAS NA AREA DE INFLUE NCIA DIRETA DO MANGUEZAL DOS RIOS TIMONHAUBATUBA ESTADO DO PIAUI BR ASIL/Links/58c57d8d45851538eb8afa97/I NTERFERENCIAS-HUMANAS-NA-AREA-DEINFLUENCIA-DIRETA-DO-MANGUEZALDOS-RIOS-TIMONHA-UBATUBA-ESTADODO-PIAUI-BRASIL.pdf. Acesso em 02/08/2019.

Odum, E. P. Fundamentos de Ecologia, Editora: Calouste Gulbenkian, Ano: 1979. Impresso.

Pascoalini, S. S.; Lopes, D. M. S.; Falqueto, R. A.; Tognella, M. M. P. Abordagem ecofisiológia de manguezais: Uma revisão. Revista Biotemas,
27 (3), setembro de 2014. Disponível em https://periodicos.ufsc.br/index.php/biote mas/article/view/31598. Acesso em 30/06/2019.

Pellegrini, J. A.C. Caracterização da planície hipersalina (apicum) associada a um bosque de mangue em Guaratiba, Baía de Sepetiba, Rio de Janeiro- RJ. 2000. 114f. Dissertação (Mestrado em Oceanografia Biológica). Universidade de São Paulo. São Paulo. Disponível em: https://www.teses.usp.br/teses/disponiveis 21/21131/tde-26112008-

134014/publico/Pellegrini.pdf. Acesso em 23/06/2019.

Penereiro, J.C.; Orlando, D.V. Análises De Tendências Em Séries Temporais Anuais De Dados Climáticos E Hidrológicos Na Bacia Do Rio Parnaíba Entre Os Estados Do Maranhão E Piauí/Brasil. (5 - 21) Rev. Geogr. Acadêmica v.7, n.2 (xii.2013). Disponível em https://revista.ufrr.br/rga/article/view/298 8/1725. Acesso em 24/03/2020.

Prost, M. T. R. C.; Rabelo, B. V. Variabilidade Fito-Espacial De Manguezais Litorâneos E Dinâmica Costeira: Exemplos Da Guiana Francesa, Amapá E Pará Boi. Mus. Para. Emilio Goe/di, sér. Ciênc. da Terra 8, 1996. Disponível em: https://repositorio.museugoeldi.br/bitstream/mgoeldi/648/1/B\%20M PEG\%20C\%20Terra\%20v8\%201996\%20P ROST.pdf. Acesso em 11/10/2019.

Sales, J. B. L.; Mehlig, U.; Nascimento, J. R.; Rodrigues Filho, L. F.; Menezes, M. P. M. Análise estrutural de dois bosques de mangue do rio Cajutuba, município de Marapanim, Pará, Brasil. Bol. Mus. Para. Emílio Goeldi. Ciências Naturais, Belém, v. 4, n. 1, p. 27-35, jan.- abr. 2009.

Santos, E. C. A.; Araújo, L. E.; Marcelino, A. S. Análise climática da Bacia Hidrográfica do Rio Mamanguape. Revista Brasileira de Engenharia Agrícola e Ambiental Campina Grande, PB, UAEA/UFCG http://www.agriambi.com.br ISSN 18071929 v.19, n.1, p.9-14, 2015. Acesso 01/07/2019.

Santos, L. C. A.; Leal, A. C. Gerenciamento de recursos hídricos no estado do MaranhãoBrasil. OBSERVATORIUM: Revista Eletrônica de Geografia, v.5, n.13, p. 39-65, jun. 2013. Disponível em http://www.observatorium.ig.ufu.br/pdfs/5 edicao/n13/03.pdf. Acesso em 25/02/2020. 
Revista Brasileira de Geografia Física v.014, n.04 (2021) 2286-2303.

Santos, P. G. P.; Oliveira, T. F. Modelagem e previsão de vazão afluente média mensal no Rio Tocantins, Usina Hidrelétrica TucuruíPará, Amazônia, Brasil. Macapá, v. 6, n. 2, p. 916, 2016. Disponível em http://periodicos.unifap.br/index.php/biota . Acesso em 21/02/2020.

Schaeffer-Novelli, Y. Perfil dos ecossistemas litorâneos brasileiros, com especial ênfase sobre o ecossistema manguezal. Publicação especial Instituto oceanográfico, São Paulo, (7): 1-16, 1989. Impresso.

Schaeffer-Novelli, Y.; Cintrón-Molero, G.; Adaime, R.R.; Camargo, T. M. Variability of mangrove ecosystems along the Brazilian coast. Estuaries (1990) 13: 204. Disponível em

http://arquivos.proderj.rj.gov.br/inea_image ns/downloads/pesquisas/RB_Guaratiba/Sch aeffer_Novelli_etal_1990.pdf Acesso em $11 / 09 / 2019$.

Schaeffer-Novelli, Y. And Clntron-Molero, G. 1988. Expedição nacional aos manguezais do Amapá, Ilha de Maracá. Relatório técnico. Brasília: CNPq, 1999. Impresso.

Jardim, M.A.G. Diversidade Biológica das Áreas de Proteção Ambiental: Ilhas de Combu e Algodoal-Maiandeua-Pará, Brasil. Belém: MPEG/MCT/CNPq, 2009. 458p. Impresso.

Silva, A. P.; Silva, J. B.; Araújo, E. D. S. Marisma, Manguezal (Mangue E Apicum): Ecossistemas De Transição Terra-Mar Do Brasil. Revista Brasileira de Geografia Física v.13, n.02 (2020) 727-742. Disponível em https://periodicos.ufpe.br/revistas/rbgfe/ar ticle/view/238388/34952. Acesso em 02/03/2020.

Silva, E. A. C. Caracterização Estrutural E Distribuição De Vegetação Arbórea Nos Bosques De Mangue Da Resex Chocoaré Mato Grosso, Santarém Novo, Pará. TCC em Ciências biológicas, Universidade Federal Rural da Amazônia, Capanema, 2018. Disponível em http://bdta.ufra.edu.br/ispui/handle/12345 6789/1260 Acesso em 12/05/2019.

Silva, J. B. Sensoriamento Remoto aplicado ao estudo do ecossistema manguezal. Tese se Doutorado, Universidade Federal de Pernambuco, UFPE, Brasil, 2012. 188p. Disponível em https://ainfo.cnptia.embrapa.br/digital/bits tream/item/76429/1/SILVA-IB.pdf Acesso em 02/08/2019.
Silva, P. K. O. C.; Silva, M. R. F. Caracterização dos Problemas Socioambientais no Ecossitema de Manguezal de Macau (RN) - Brasil. Revista GeoInterações, Assú, v.3, n.1, p.42-65, jan./jun. 2019. Disponível em http://periodicos.uern.br/index.php/geoint eracoes/article/view/3537/2065 . Acesso em 04/03/2020.

Soares, M. L. G.; Chaves, F. O.; Estrada, G. C. D.; Cavalcanti, V. F.; Portugal, A. M. M.; Barbosa, B. Caracterização das florestas de mangue do complexo estuarino de Caravelas (BahiaBrasil). Bol. Téc. Cient. CEPENE, Tamandaré PE - v. 16, n. 5, p. 23-41, 2008. Disponível em: https://www.researchgate.net/profile/Gust avo Estrada/publication/256444396 CARA CTERIZACAO DAS FLORESTAS DE MANGUE DO COMPLEXO ESTUARINO DE CARAVEL AS BAHIA-

BRASIL/Links/0deec5229e3b1aeba900000 O/CARACTERIZACAO-DAS-FLORESTAS-DEMANGUE-DO-COMPLEXO-ESTUARINO-DECARAVELAS-BAHIA-BRASIL.pdfAcesso em 25/05/2019.

Soares, M. L. G. Estrutura vegetal e grau de perturbação dos manguezais da Lagoa da Tijuca, Rio de Janeiro, RJ, Brasil. Rev. Bras. Biol. vol.59 no.3 São Carlos Aug. 1999. Disponível em: Rev. Bras. Biol. vol.59 no.3 São Carlos Aug. 1999. Disponível em http://www.scielo.br/scielo.php?script=sci_ abstract\&pid=S0034$\underline{71081999000300016 \& \operatorname{lng}=e n \& n r m=i s o \& t 1}$ $\underline{\mathrm{ng}=\mathrm{pt}}$ Acesso em 03/06/2019.

Souza Sobrinho, R. J.; Bresolin, A.; Klein, R. M. Os Manguezais na Ilha de Santa Catarina. v. 2 (1969). Disponível em: https://periodicos.ufsc.br/index.php/insula/a rticle/view/13192/12243. Acesso em 05/06/2019.

Souza Filho, P. W. M. Costa de Manguezais de Macromaré da Amazônia: Cenários Morfológicos, Mapeamento e Quantificacão de áreas usando dados de sensores remotos. Revista Brasileira de Geofísica, Vol. 23(4), $2005 . \quad$ Disponível em: https://sbgf.org.br/revista/index.php/rbgf/ article/viewFile/1581/747. Acesso em $11 / 06 / 2019$.

Souza, H. F.; Guedes, M. L. S.; Oliveira, S. S.; Santos, E. S. Alguns Aspectos Fitossociológicos E Nutricionais Da Ilha De Pati-Bahia-Brasil. Sitientebus, Feira de 
Revista Brasileira de Geografia Física v.014, n.04 (2021) 2286-2303.

Santana, n. 15, p151-165. 1996. Disponível em:

http://www2.uefs.br/sitientibus/pdf/15/al guns aspectos fitossociologicos e nutriciona is.pdf Acesso em 12/02/2019.

Taiz, L.; Zieger, E. Fisiologia vegetal. Trad. SANTARÉM, E. R. et al., $3^{\circ}$ ed., Porto Alegre: Artemed, 2004. 719p.

Tessler, M. G.; Goya, S. C. y. Processos Costeiros Condicionantes do Litoral Brasileiro. Revista do Departamento de Geografia, 17 2005) 11-23. Disponível em http://www.periodicos.usp.br/rdg/article/vie w/47271/51007. Acesso em 23/05/2019.

Torres, A.; El-Robrini, M. Erosão E Progradação Do Litoral Brasileiro | Amapá. $2020 . \quad$ Disponível em https://www.mma.gov.br/estruturas/sqa_sig ercom/_arquivos/ap_erosao.pdf. Acesso em 23/02/2020.

Vargas, R. K.; Alberti, L. F.; Souza, A. M.; Wolf, L. Estrutura de uma floresta de mangue na Baía da Babitonga, São Francisco do Sul, SC Ciência e Natura, vol. 33, núm. 2, 2011, pp. 57-72. Disponível em https://www.redalyc.org/pdf/4675/4675463 60004.pdf. Acesso em 14/06/2019.
Vital, H. Erosão E Progradação Do Litoral Brasileiro | Rio Grande Do Norte. Disponível em:

https://www.mma.gov.br/estruturas/sqa si gercom/ arquivos/rn erosao.pdf. Acesso em 02/01/2020.

Vila Nova, F. V. P., Torres, M. F. A.; Coelho, M. P. Composição Física-Química De Solos Em Espécies Arbóreas Do Ecossistema Manguezal. Acta Geográfica. set-dez 2017, vol.11, Issue 27, p1-19.19p. Disponível em https://revista.ufrr.br/actageo/article/view 3034/2479. Acesso em 13/04/2019.

Walsh, G. E. Mangroves forests: a review. In: Reimold, R. J.; Queen, W. H. Ecology of halophytes. New York: Academia Press, p. 51174, 1974. Disponível em https://books.google.com.br/books?hl=pBR\&lr $=\& \mathrm{id}=\mathrm{s} A 6 q i 1 \mathrm{ydg} \_\mathrm{kC} \& o \mathrm{i}=$ fnd $\& p g=\mathrm{PA} 51 \& \mathrm{dq}=$ walsh+mangroves: $+a+$ review \&ots=tYOMO07u4\&sig=YKLvAdyoLjWzXDHgTGUlv4rKr7Y \#v=onepage \&q=walsh\%20mangroves $\% 3 \mathrm{~A} \% 20$ a\%20review\&f=false. Acesso em 19/04/2019. 